\title{
3D modelling of strip reinforced MSE wain
}

\author{
I. P. Damians $s^{1,3} \cdot$ R. J. Bathurst ${ }^{2}$ (1) $\cdot$ S. Olivella ${ }^{1,3} \cdot$ A. Llor $t^{1} \cdot$. Josa ${ }^{1}$ \\ Received: 1 March 2020 / Accepted: 11 August 2020 \\ (C) Springer-Verlag GmbH Germany, part of Springer Nature 2020

\section{Abstract}

This paper reports the results of 3D numerical odelling of a 6-m-high mechanically tabnised earth (MSE) wall constructed with concrete panels and steel or pol nerro strip reinforcement. These systems o ose numerical challenges as a result of the discontinuous reinforcement arr $n g \mathrm{~m}$-nt which is not the case for MCE wals constructed with continuo s reinforcement layer configurations. Deta of $t$ numerical approach includind modoling of the reinforcement strips, concrete facing panels and compressible be ang pads between panels are described. s amples of numerical prediction s for facing deformations, toe loads due thon wn-drag behind the panels, sc 1 ho reinforcement settlements, and in forcement tensile loads are presented. Thu influence of reinforcement s ness comonstrated by comparing $n$ predictions for the same MSE wan with relatively inextensible steel strips na ith relatively extensible polymeric stros. Of particular interest are the results shuving the disruption of earth along vertical and horizontal planes in the reinforced soil zone as a resul of $\mathrm{t}$ - discontinuous strip inclusions, and the vertical load that accumulan on the reinforcement strips close to the cor ve tions due to soil settlement behind the facing. The details of the moc ellim approach used here and the lessons le arne provide a benchmark for future similar lines of investigation and fo nractitioners, particularly as the computation 1 power of desktop computer continues to increase.

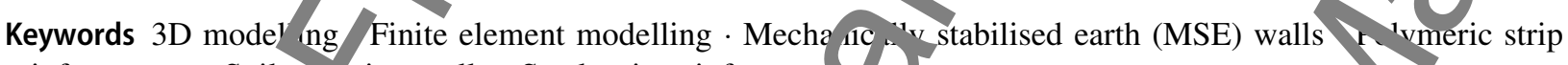
reinforcement $\cdot$ Soil reta aing walls $\cdot$ Steel strip reinforcement

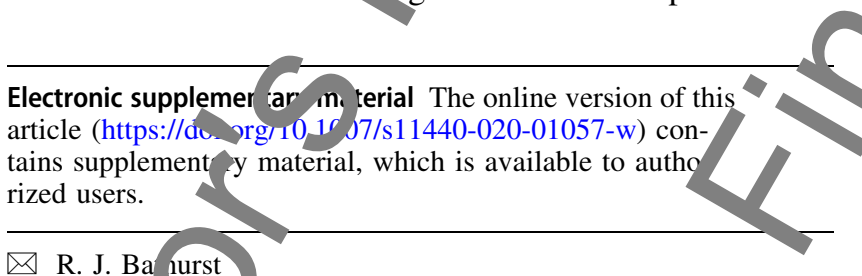

J. Ba ourst

bathurstn hard ggmail.com

LP. Dann

ivar..rig@upc.edu

5. 'vivela

Shastia.olivella@upc.edu

A. I loret

antonio.lloret@upc.edu

A. Josa

alejandro.josa@upc.edu

1 Department of Civil and Environm ntal Engineering, School of Civil Engineering, Univer Polntenica de CatalunyaBarcelonaTech (UPC), Bard'ona, spain

2 GeoEngineering Centre a Oueer s-RMC, Civil Engineering Department, Royal Military Lurege of Canada, Kingston, ON K7K 7B4, Can da

3 International Center fo. Numerical Methods in Engineering (CIMNE), Universitat Po tècnica de CatalunyaBarcelonaTech (UPC), Barcelona, Spain

\section{Introduction}

Mechanically stabilised ar h MSE) walls constructed with incremental concrets fa $\mathrm{g}$ panels and discontinuous strip reinforcement el ments are a well-established technology. The soil-reinfor ment elements most often take the form of st el strips, steel grids or polymeric strips. Other systems se teel rod and anchor arrangements. This paper is focused onstrip-type soil reinforced soil walls. The internal stability design of these structures is most often based or i mit equilibrium methods with empirical adjustnots apn ed to familiar concepts of earth pressure theory. he most common limit states for internal stability are reinto ement pullout, reinforcement rupture and connect on 1s lure between the soil-reinforcement and wall facirinis. For MSE walls constructed with continuous $1 \mathrm{Cn}$ cement layers in the running wall face direction, 2D (1 'ane strain) analyses are appropriate. Examples are walls onstructed with continuous sheets of geogrid, geotextile and steel grids (bar mats and welded wire). For disconnuous reinforcement systems, 2D limit equilibrium-based analyses are useful approximations suitable for design of 
routine wall structures for ultimate (failure) limit states (e.g. $[1,11,18])$. Nevertheless, these approaches cannot be used to explicitly predict performance features related to wall deformations for discontinuous and continuous reinforcement cases because they are force based. The challenge to model walls under operational (working stress) conditions is greater for discontinuous reinforcement material cases than for continuous sheet-like reinforcement arrangements. Ideally, 3D numerical modelling using th finite element method (FEM) and finite difference meth (FDM) is best suited for this purpose.

The objective of the current study was to develop 3D FEM model to simulate the construction and en ${ }^{c}$ construction performance of a typical concrete panel TSE wall of height $H=6 \mathrm{~m}$ constructed with steel stri anowith soil materials having a range of properties. hh in rdth of the model is $1 \mathrm{~m}$ corresponding to the re $\mathrm{r}_{\mathrm{H}}$ ing of the wall (i.e. width of one-half panel).

The model geometry for the reinf and panels in this study is typical of actual structures. vowever, rather than matching the material propu ties for the component materials, interfaces and foundation to a particular constructed wall structure, values $\mathrm{w}$ re cted from prior $2 \mathrm{D}$ modelling of walls reported in he literature and the experience of the writers an co yorkers with $2 \mathrm{D}$ modelling of other MSE walls (e.s [19, 21, 23, 49, 50]).

The incremental co struct of the wall was simulated in the numerical mo elli g. Performance results at end of construction for wall al lacements, reinforcement loads, and horizontal and vertical earth pressures are reporter The base case for ane current investigation is a steel sth MSE wall. S sit ty halyses were carried out to inv tigate the inf aence on wall performance of diff rent properties assiy to the backfill soil, foundation 1, the horizontal ean $g$ pads located between panels, stiffness of the strip 1 infor ement (e.g. more extensible polymeric strips), an soll-facing and soil-strip interfaces.

Thm study is the first to model a tall (6-m-high) MSE soils all using a 3D FEM approach wi h $41 \mathrm{~s}$ rete strip rein 'orcement inclusions having very dirierent -iffness and range of other component model pr berties. The details of th modelling approach used bare and the lessons anred provide a benchmark for futur similar lines of investigation, particularly as compuational power of aesktop computers continue to incronse.

\section{Prior related work}

Examples of numer ran cEM modelling of MSE walls with continuous reinfo ment layers and different types of hard concrete facing can be found in the literature. Thes include the work of Cai and Bathurst [12], Karpure
Bathurst [32], Rowe and Ho [42], Rowe and Skinner [43], Yoo et an [48], and Ling and Leshchinsky [34], amongst many Ours. Similar attempts using the finite difference meth $\mathrm{d}(\mathrm{F}) \mathrm{M})$ can be found in the papers by Hatami and Bat rst [ 6, 27], Huang et al. [29], Dal no et al. [20] and u et al. [49]. Many of these pape ave demonstrated satistuctory predictions of import tt $m$ casured performa ce features of instrumented fun ccar walls in the field and in the laboratory.

2D numerical models using CEM and FDM approaches have been used to simulate he pe formance of hard face concrete walls constructe witn discontinuous steel and polymeric strip reinforc $m$. nt (e.g. [2, 9, 13, 17, 19, 21, 23, 49, 53]), and ste anchors [46]. However, in these studies it was necessavy to o onvert the discrete reinforcing strips to equivalent antiruous layers.

The modelling of MSE walls with discontinuous reit forcing elements ${ }_{151 H_{0}}$ a 2D model has been recognis $d$ as an imperfect ip ro $\mathrm{h}$ because the distribution of stresses in he co-plane direction is interrupte $b$ he reinforceme, th lusions [38].

$3 \mathrm{D}$ ment modelling of MSE walls wh continuous gevnthetic reinforcement can been to nd in the literature (e.g. [47, 24]). However, the $3 / \mathrm{m}$ dels were required to account for the 3D problem reometry and discontinuous surface loading. The re al cement layers we. modelled as planar sheets.

4o and Smith [28] report an ea ottempt at true 3D 10 elling of the steel strips in a reint rced soil wall. They used brick elements to model tho repeatung column of soil, reinforcement and the facing panels, and a second adjacent column of elements to mode the uninterrupted soil. The width of the reinforced so lum matched one-half the reinforcement width, and h to o columns together had a width equal to one-ha ${ }^{1 \times}$ the norizontal spacing between reinforcement inclusi is. Contours of shear stresses were very different at ver ical surfaces taken though the middle of the reinfor ement stups and parallel surfaces taken through the in $\mathrm{n}$ ediate unreinforced soil zone.

Bourgeois et al. 9 used a homogenisation approach to account for the discrete reinforcement strips and the soil in a 3D FEM si 4 ation of a steel strip reinforced wall of height $\$ .74 \mathrm{~m}$ apporting an embankment for a railway track sir ulated by a pair of footings. Their finite element mesh comr ised of 5000 nodes and 2000 elements. The sam tean carried out a 3D FEM simulation of the same probin s y using 50,000 nodes and modelling the reinf orcent strips with "friction bar elements" developed sp cially for the FEM program used to carry out the simTations [10]. The latter work is the closest related study to the current investigation. However, the general approach nd the scope of their paper and the current study are very different.

\section{(1)} $\hat{x}^{x}$ . 


\section{Numerical approach}

\subsection{General}

The computer software program CODE_BRIGHT [14, 39] was used to carry out the numerical simulations in this study. This program was used because it is freely available, is familiar to the writers and can accommodate large 3D geomechanics problems. It has a number of advance $a$ constitutive models available in the software librar However, simple models described later were adopted the current study. The calculations were performed in mall strain mode to keep simulation runtimes mar a able. Regardless, the objective of the numerical mode ling was to investigate wall performance under wo sing siress conditions consistent with the notion of sn all strain deformations.

\subsection{Finite element model}

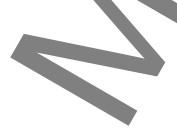

Figure 1 gives an overview of the model and wall components. The model geomet $y$ for he reinforced zone and panels captures the principal fe tr es of a typical steel strip reinforced soil wall wh te an pting simple geometry and boundary conditions to ansure that computational demands were not ex essive. The properties of the component materials and nte aces are taken from prior related 2D modelling of MSE ${ }^{11}$ s by the writers and co-workers as explained later.

The numerical $\mathrm{sic}$ represents an idealised $1-\mathrm{m}$ wit repeating uni in $\mathrm{dir}$ ection of the running lengt ${ }^{1}$ of wall with pane $1.5 \mathrm{~m}$ high. The steel reinforcem $\mathrm{nt}$ sips are taken as $\mathrm{mm}$ wide by $4 \mathrm{~mm}$ thick and p. ed at vertical spa $1 \mathrm{II}_{\mathrm{B}}$ of $0.75 \mathrm{~m}$; these are typical dimensions wor these syste is (e g. [25, 45]).

The anerical model represents a 6-m-high wall with four $\mathrm{p}$ els. The length of the reinforced zone is about $L=2 \mathrm{~m}$ which is $0.7 H$ where $H$ is th $\mathrm{v}$ all height. A rat of $L / H=0.7$ is a typical recommenda value for design c.g. [1]). The numerical simula ons did not include any surcharge at the top boundary of the podel.

rigure 2 shows mesh and mate ial $\mathrm{p}$ operty zones for the panels, reinforcement and conno ns. Careful attentwon was paid to the beari oad $\triangle$ ne dimensions and assignment of properties recan previous numerical modelling by the writers has Sir that these details have a critical influence on facing - haviour for these types of walls (e.g. [19]). The figur sh ws that the steel strip layer is $50 \mathrm{~mm}$ wide by hm $5 \mathrm{~mm}$ dimension was selected to facilitate a ptimum level of mesh discretisation. However, the prop ties for the base case steel strip models in this study were adjusted (Eq. 1) to mat strips that are $4 \mathrm{~mm}$ thick and placed at typical $0.75 \mathrm{~m}$ horizolrta centre-to-centre spacing between strips in each reinf ico ent layer [2]. Hence, for base case calculations usit a $1 \mathrm{~m}$ horizontal spacing, the reduced equivalent elas mulus of the steel (per unit inning length of all) $\left(E_{\text {eq }}\right)$ was computed to give ame stiffness of $J_{\mathrm{r}}=\$ 6 \mathrm{MN} / \mathrm{m}$ for a $4-\mathrm{mm}$-thick ste 1 stri as follows:

${ }_{\mathrm{eq}}=\frac{J_{\mathrm{r}}}{A_{\mathrm{r}, 3 \mathrm{D}}}=224 \mathrm{GPa} / \mathrm{m}$

where $A_{\mathrm{r}, 3 \mathrm{D}}$ is the reinforcem nt cry ss-sectional area of the model (i.e. $A_{\mathrm{r}, 3 \mathrm{D}}=50 \mathrm{~mm}$ wiu $\times 5 \mathrm{~mm}$ thick $=2.5 \times$ $10^{-4} \mathrm{~m}^{2}$ ) and $J_{\mathrm{r}}$ is the $\mathrm{xi}$ inforcement stiffness per running metre of wall, -lculued as:

$J_{\mathrm{r}}=(E A)_{\mathrm{r}}\left(\frac{n_{\mathrm{r}}}{L_{\mathrm{p}}}\right)=56 \mathrm{~N} / \mathrm{m}$

where $(E A)_{r}$ is the reinforcement axial stiffness (i.e. elastic modul $S \quad D r$ the reinforcement $\left(E_{\mathrm{r}} \simeq 210 \mathrm{O} \cdot \mathrm{D}\right)$ times the oss- $a_{10}$ area of the reinforcen en t $r$ r$=50 \mathrm{~mm}$ ido $4 \mathrm{~mm}$ thick $=2.0 \times 10^{-4} \mathrm{~m}^{2}$ mat $\mathrm{h}$ ing th a coported by Abdelouhab et al. $\left[2 ; n_{\mathrm{r}}\right.$ is the numbo of reinforcement strips per panel $\left(m_{1}-3\right)$; and $L_{\mathrm{p}}$ is the length of a panel $(1.5 \mathrm{~m})$. Thus, $n_{1} L_{\mathrm{p}}$ rresponds to the horizontal centre-to-centre spacing hetween reinforcement strips of $0.75 \mathrm{~m}$.

Sioure $1 \mathrm{~b}$ shows small elements wit $\mathrm{S}$ ffter material (t) ctic modulus $=0.1 \mathrm{MPa}$ ) that introduced in the un erical mesh at the end of the rein orcement to prevent the development of a numerical $\mathrm{r}$. $\mathrm{d}$ spot that can act as an anchor and therefore artificially over-siffen the reinforced soil zone. The width and Might of each element are $150 \mathrm{~mm}$ and $105 \mathrm{~mm} \mathrm{(F/2} \mathrm{2b)} \mathrm{and} \mathrm{occupy} \mathrm{the} \mathrm{last}$ $100 \mathrm{~mm}$ at the free end o th $\mathrm{y}$ inforcement.

All elements in the rite rement mesh were 8-noded hexahedra including r nes used to simulate the interfaces between dissimilar nater. The finite element mesh was composed of 17,318 elements with 13,800 nodes.

The botton do nain boundary was fixed in numerical simulations. The to dation boundary at $4.5 \mathrm{~m}$ below the wall was judged to be far enough away not to influence numerical ut 0 es in any practical way. The vertical $y$ $z$ bounumies we fixed in the cross-plane $(x)$ direction. Hence, he soil and panel $y-z$ boundaries in the vertical (y) directro were free to move. The domain boundaries at the ront $f$ the foundation zone and at the back of foundation an retained fill zones were free to move in the ertio direction. The distance of the wall facing from the bu $\mathrm{k}$ boundary of the domain $(8.2 \mathrm{~m}$ in Fig. 1) was lected as a practical compromise to minimise far-field houndary effects on wall facing deformations and computition time. Furthermore, the length of the retained fill is large enough to contain a potential active wedge 


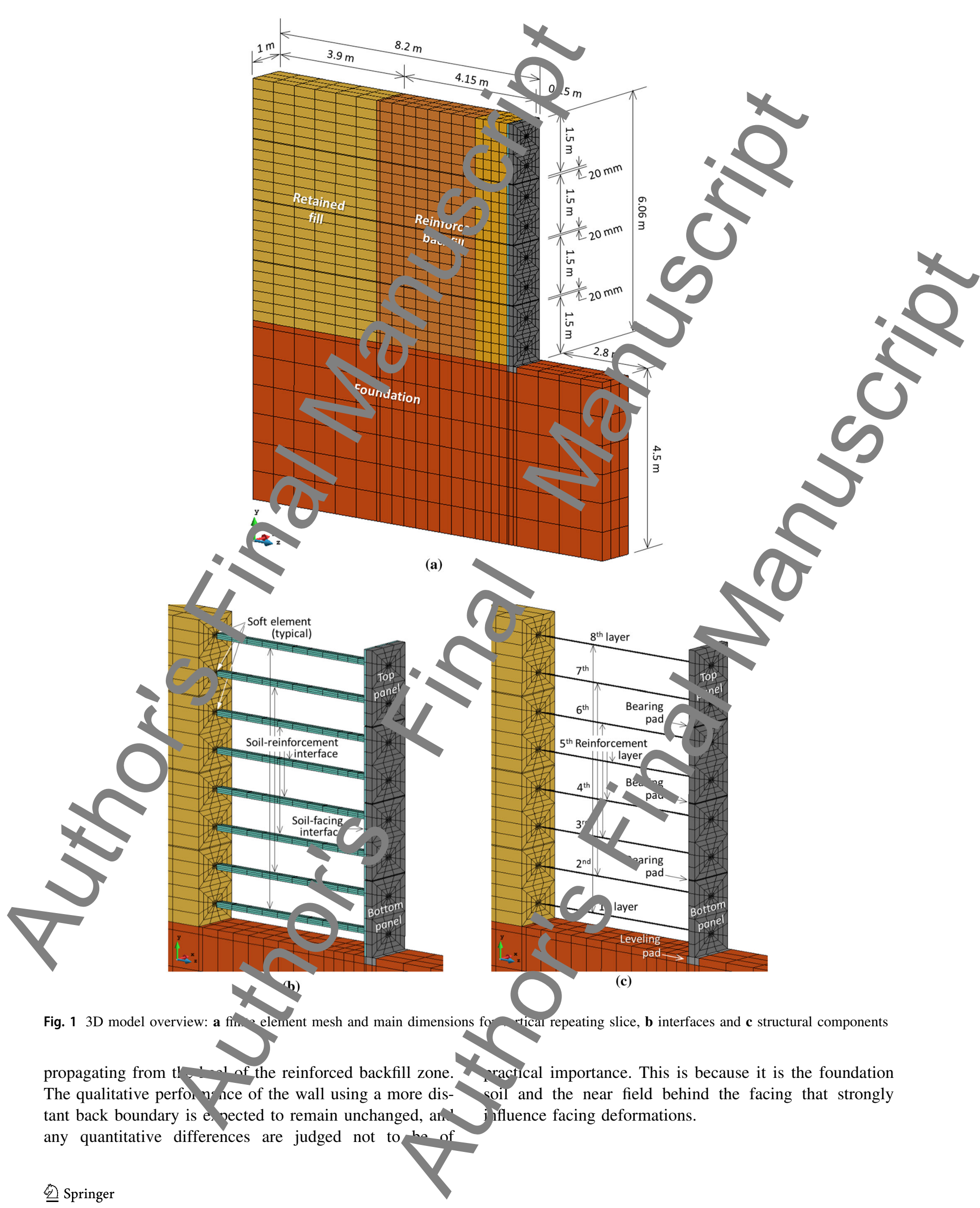




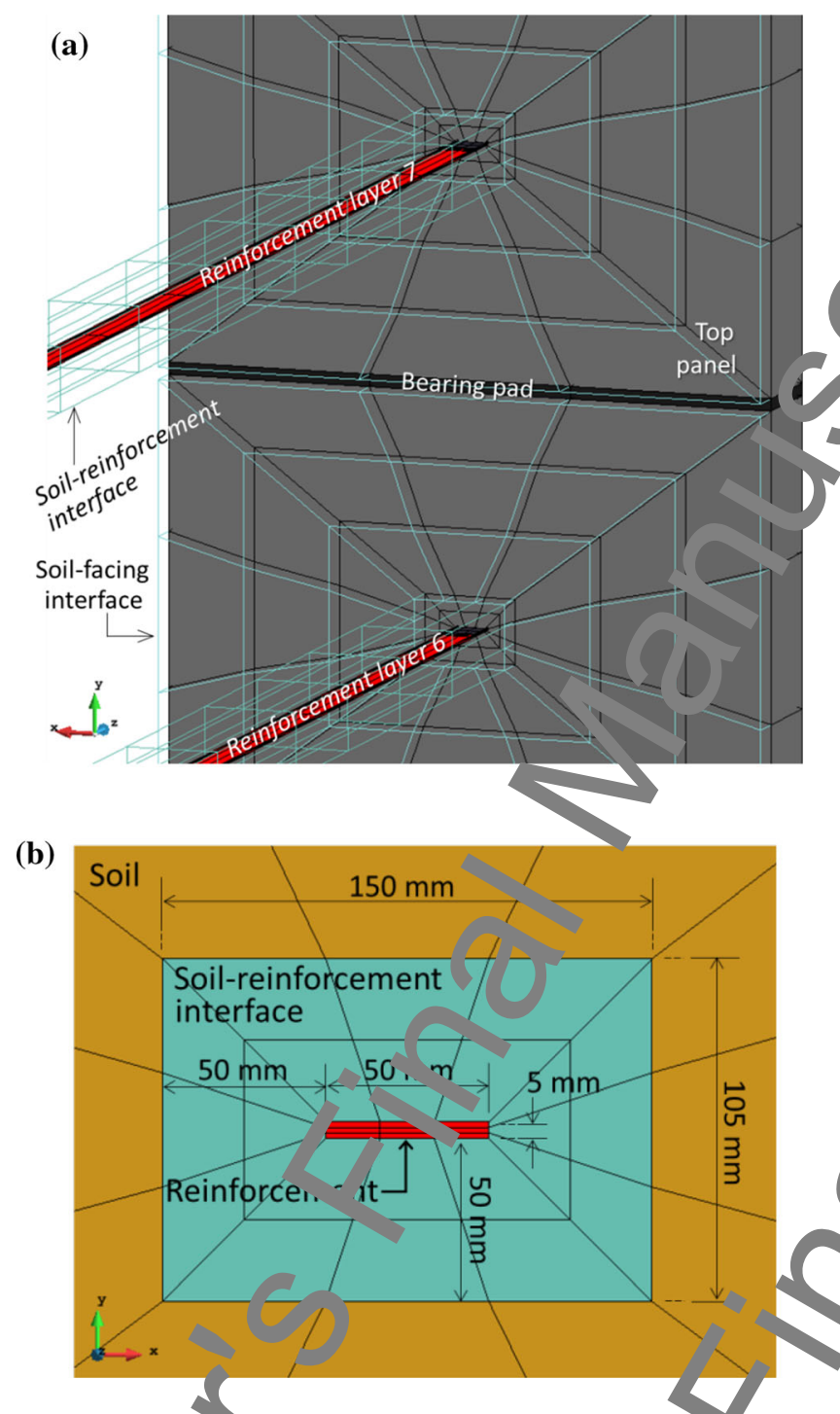

Fig. 2 Mesh and merial property zones for the panels, re forcement and $c$ nnee ons: a facing panel joint and reinforcement connections, nd $\mathbf{b}$ ertical slice through reinforcement strip showing soil interfone zun

'e numerical model was constructer in o tges. The foundatio zone was turned on first. Then the first panel was $p_{1}$ ved together with the concrete levelling pad. This pan was restrained horizontally to sm ulate the panel caus that are used to temporarily appos the panels in the ield. The soil layers and reinforce an layers were then praced in two steps. The acc nd p nel was placed and braced after the first $0.75 \mathrm{~m}$ of il was in place. Once all the soil behind the second pan was in place, the support for the bottom panel was rem ved. The same staged construction was repeated to the remaining panel units as illustrated in Figur ${ }_{1}$ in the Supplemental Material for this paper.

Compaction of the so layers was not simulated direct in this study. However, the reinforced backfill soil located withir the first $1 \mathrm{~m}$ beyond the wall face was assigned a lower no 'ulus value than the remainder of the reinforced zone as plained in the next section.

S. hulat ons were performed on a PC using one Into $\mathrm{R}$ ) vre(TM) i7-8850H CPU prossor running at $30 \mathrm{GHz}$ (maximum turbo frequencr and with $32 \mathrm{~GB}$ of RAlw memory. The elapsed CPU ti for he cases in this stu y varied from 20 to $50 \mathrm{~h}$.

\subsection{Material properties}

\subsubsection{Base case}

As noted earlier, the bas cas for the numerical modelling in this study is the $6-\mathrm{m}-\mathrm{h}$ g $\mathrm{n}$ wall reinforced with stcel strips shown in Fig 1 Mruerial types and properties use 1 in this study are s mmarsed in Tables 1, 2, 3 and 4. Thu material properties us $d$ in the base case analysis are s' own in the shaded ell, Table 4.

Allen $\mathrm{Ba}$ h rst [5] have demonstrated t at $m$ ll performance is nsitive to reinforcement global suffe ss $\left(S_{\mathrm{g}}\right)$ w sumputed as the reinforceme stiffness $\left(J_{\mathrm{r}}\right)$ n all reinforcement layers divian $b$ wall height $(H)$. For example, wall reinforcer ent 'oads will increase with greater global reinforcement tiffness when all other properties remain unchanged. The alue of $S_{\mathrm{g}}$ was con nuted as $42 \mathrm{MPa}$ (Table 4) which fal s within the $r_{\text {; }}$ re of 30-400 $\mathrm{MPa}$ reported by $A$ ' $\mathrm{c}$ and Bathurst $[5,6]$ as $\mathrm{d}$ on data taken from 24 full-sca instrumented steel strip reinforced soil walls unas operational conditions. These walls were judged to fall wrthin the inextensible reinforcement category. Tho maximum steel strip reinforcement strains for all as and layers in the current study were less than $0.03, v \mathrm{~h}$ ch is well below the yield strain of $0.2 \%$ for the 1 . For comparison, a monitored 17-m-high production teel strip wall described by Runser et al. [45] recorded ctram up to $0.08 \%$ at end of construction. The omputea maximum strains for the polymeric straps in paper were about $0.2 \%$ which is at the low end of values asured in actual PET strap walls and is well below $1 \%$ strain that is recommended to keep these systems at WO $\mathrm{ig}$ stress levels [36] and to ensure adequate magins safety against tensile failure [8].

All s il materials were assumed to be linear elasticplastic Th soils are granular type with shear strength best desc ibed y peak plane strain friction angles. Plane strain frictio gles of a granular soil can be determined from a "plam strain" test apparatus that confines a block of soil bu veen two frictionless parallel plates that prevent out-ofI are deformations at the plate boundaries. Hence, this test oparatus constrains the soil similar to the $y-z$ boundaries i the numerical model used in this study. Peak friction angles computed from plain strain tests for dense granular 
Table 1 Soil material properties for base case taken from Yu et al. [49]

\begin{tabular}{|c|c|c|c|}
\hline \multirow[t]{3}{*}{ Parameter } & \multicolumn{3}{|l|}{ Soil material } \\
\hline & Backfill $^{\mathrm{a}}$ & & Foundation \\
\hline & $(>1.0 \mathrm{~m} \text { from face })^{\mathrm{b}}$ & $(<1.0 \mathrm{~m} \mathrm{fr}$ & \\
\hline Unit weight, $\gamma_{\mathrm{n}}\left(\mathrm{kN} / \mathrm{m}^{3}\right)$ & 18 & & 20 \\
\hline Elastic modulus, $E(\mathrm{MPa})$ & 20 & 10 & $45^{\mathrm{c}}$ \\
\hline Poisson's ratio, $v(-)$ & 0.3 & & 0.3 \\
\hline Cohesion, $c(\mathrm{kPa})$ & 1 & & 5 \\
\hline Friction angle, $\phi\left(^{\circ}\right)$ & 44 & & 36 \\
\hline Dilatancy angle, $\psi\left({ }^{\circ}\right)$ & 14 & & 6 \\
\hline
\end{tabular}

Table 2 Non-soil material properties for base case

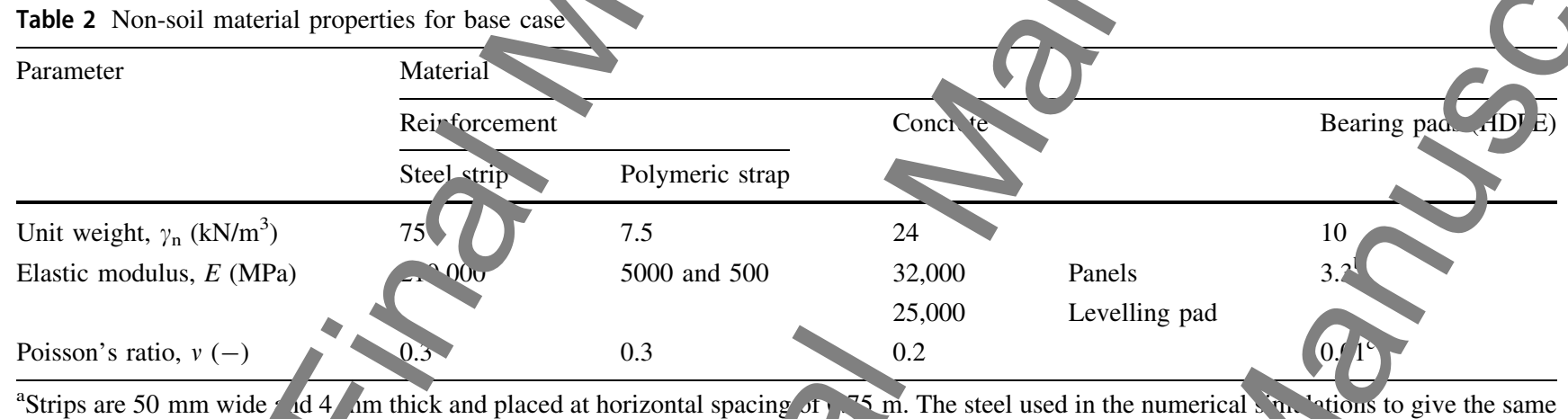

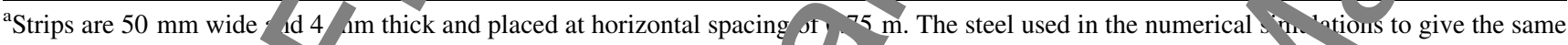
stiffness using a $5 \mathrm{~mm}$ tho strip $J=56 \mathrm{MN} / \mathrm{m}$

${ }^{\mathrm{b}}$ Equivalent modulus of horizontal joint material for 1-m running len of wall based on two HDPE bearing pau nlacen $1.5 \mathrm{~m}$ intervals for a typical physical wall [16, 23]

'Negligible Poisson' ro of lue to account for internal spaces (noids) and ribbed geometry which reduces ateral expansion of each pad under vertical compresson

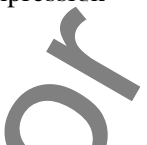

Table 3 Inter aterial properties for base case (data from [49])

\begin{tabular}{|c|c|c|}
\hline Parain $t$ & Interface & \\
\hline & Soil-facing ${ }^{\mathrm{a}}$ & Soil-reinforcement \\
\hline Unit $m$ rht, $\gamma_{\mathrm{n}}\left(\mathrm{kN} / \mathrm{m}^{3}\right)$ & 19 & 19 \\
\hline Er. tic iffness modulus, $E$ (MPa) & 4.02 & 20 \\
\hline . & 0.45 & 0.45 \\
\hline Cohesion, $c(\mathrm{kPa})$ & 0.6 & 1 \\
\hline riction angle, $\delta\left(^{\circ}\right)$ & 30.1 & $26.6^{\mathrm{b}}$ \\
\hline Dilatancy angle, $\psi\left({ }^{\circ}\right)$ & 0 & $14^{\mathrm{c}}$ \\
\hline
\end{tabular}

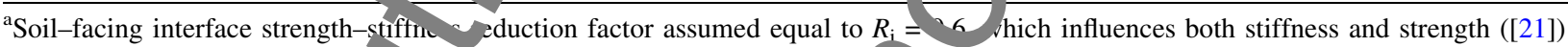

${ }^{\mathrm{b}}$ Soil-reinforcement steel strip inter, tion assuming $\delta=26.6^{\circ}\left(=\phi_{\mathrm{i}}\right)$ i ec livar to an interface reduction factor of $R_{\mathrm{i}}=\tan \delta / \tan \phi=0.52$, which corresponds to a pullou "rictic , factor $F^{*}=\tan \delta=\tan \left(26.6^{\circ}\right)=0$. (i.e. $\left.F^{*}=\tan \delta=R_{\mathrm{i}} \tan \phi=0.52 \tan \left(38^{\circ}\right)=0.40\right)$. The base case $F^{*}=0.4$ in the current atudv and matches AASHTO [1] specifications or smosth steel strips but is low for ribbed steel strips and polymeric strips [37]. This value is assu seu to remain constant at reinforcemen - ocatus deeper than $3 \mathrm{~m}$ from top of wall (i.e. all reinforcement layers modelled), which is in goo agreement with results of Chida and Nakaga ${ }^{[15]}$ and numerical results reported by Yu et al. [49]. According to FHWA [25], the friction ang of the soil to compute $F^{*}$ is based on the eak friction angle from triaxial or direct shear tests

${ }^{\mathrm{c}}$ Assumed equal to backfill soil dilatancy angle for soil-rein mant interface material zone 
soils are larger than values deduced from triaxial tests. Using the relationship proposed by Kulhawy and Mayne [33], the peak plane strain friction angle of $44^{\circ}$ corresponds to $38^{\circ}$ from triaxial tests. This value is typical for high quality granular fill materials that are recommended in AASHTO [1] specifications for MSE walls. A value of cohesion $c=1 \mathrm{kPa}$ was selected to ensure numerical stability at the soil zone (top) free boundaries during construction (e.g. [19]). The elastic modulus of the soil locate $a$ within $1 \mathrm{~m}$ of the back of the wall facing was reduced $50 \%$ to capture the effect of lower compaction energy this region when lighter compaction equipment is used directly behind the facing as recommended for g o construction practice [25]. This reduced soil mod us technique for this zone has been used in 2D sip -1ations of other MSE walls for the same reason giv n ie. (e.g. $[19,49])$.

The modulus and friction angle propert s on the interfaces were related to the adjacent so womo reduction factor $\left(R_{\mathrm{i}}\right)$. This value was set to 0.6 for the facing-soil interface and 0.52 for the soil-rein arcement interface. The facing-soil interface was assumed to o smooth and thus non-dilatant while the soil-rei for co ent interface was assumed to be rough and therefore $\mathrm{w}$ assigned the same dilatancy angle as the adjace $t$ son The choice of soil and interface parameters used her was based on experience from 2D modelling if stee strip reinforced walls by Damians et al. [21] hd / et al. [50]. The friction coefficient for the base case as assumed as $F^{*}=0.4$ which is at the low end for polymeric strips $[2,35,36]$ and a cor servative (safe) es im ${ }^{\text {ta }}$ for design with ribbed steelstrip [1].

The mecha ical properties of the horizor al sint between adjac panels were selected to transio the bearing parth are constructed with internal voids and ribbed gec netry to a continuous thin solid rectangular strip zo with equivalent one-dimensional compressive stiffno $\left(E_{\mathrm{p}}\right)$. The joint material for base ase models is

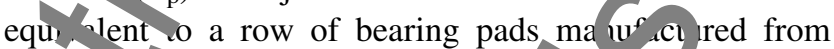
hig density polyethylene (HDPE) [23

3.3. -dditional cases and material nmoter ies for sensitivity analyses

Farametric analyses were an ied in this study to examine the influence of rars of soil and material properties on numerical moden outcomes. Nine additional numerical simulations ere carried out using the combinations of values sho in $n$ Table 4 . Included in the parametric analyses wom with polymeric strips that were assigned tensilu iffness values of $J_{\mathrm{r}}=1.25$ and $0.125 \mathrm{MN} / \mathrm{m}$ (load per $\mathrm{m}$ width of strap). These values ar at the top and bottom range of secant stiffness computed at $1000 \mathrm{~h}$ and $2 \%$ strain from constant load tests [7]. The - rresponding global reinforcement stiffness values $=1.7$ and $0.17 \mathrm{MPa}$, respectively. The higher stiff ss c se is in agreement with eight instrumented field wat exan ined by Miyata et al. [36] th. were constructed ith modern polymeric (PET) strips anown to have $S_{\mathrm{g}}$ valuos in the range of 1.96-0.79 M Th lower value in the current study falls below the fic cas noted above but was selected in one set of analys s to explore the influence of reinforcement stiffness on cumvical outcomes. Allen and Bathurst [6] showed that walls constructed with other types of relatively exten ble polymeric reinforcement products (i.e. geogrids $a$ feotextiles) can also be expected to have $S_{\mathrm{g}} \leq \mathbf{\Delta}$ inuang values that are less than $S_{\mathrm{g}}=0.17 \mathrm{MPa}$ in the currel $\mathrm{l}$ study.

Analyses were $2^{10}$ canied out with different backf and foundation m dulus values $\left(E_{\mathrm{b}}\right.$ and $\left.E_{\mathrm{f}}\right)$ and a mor compressible benring ad arrangement. Numerical mulations were $\mathrm{r}$ pe to - with a lower interface strength nd stiffness Mctic actor $\left(R_{\mathrm{i}}\right)$. Finally, calculati ns in th different so $1-1$ inforcement pullout friction factor $F^{*}$ assign ch reinforcement layer were pen med. Based on ASHTO [1] recommendations, the rs for ribbed steel strips were assigned values of $\mathrm{B}^{*}$ linearly interpolated between 0.80 at the bottom of wall and 2.0 at the top of the wall.

\section{. (1) \\ (2) \\ I Todel approach applied tc PWRI wall case study}

Many of the baseline moder arameters were taken from the paper by $\mathrm{Yu}$ et al. [49] modelled the instrumented steel strip wall constructe $t \mathrm{t}$ e Public Works Research Institute (PWRI) in $\mathrm{J}_{\mathrm{T}} \mathrm{n}$ and reported by Chida and Nakagaki [15]. In ord to develop confidence with the 3D model developed fo this udy, the measured and numerically predicted einforcentent loads and wall toe load from the earlier sum by the writers and co-workers were revisited [49]. The aterial properties for the PWRI wall numerical analysis are identified in the tables presented earlier. It $s$ ro a be noted that the PWRI wall was a test wall supportin a narrow embankment with an inclined surchar and was constructed with cruciform shape facing panels Ho ce, the general arrangement was more complic ted an the $3 \mathrm{D}$ wall slice that is the focus of the curre dy.

Fro 3 shows the measured reinforcement loads to ther with predictions using the same CODE_BRIGHT D FEM code as in the current study (i.e. using a 3D nalysis) and two other commercial 2D numerical modlling codes (FEM - [40, 41]; FDM - FLAC- [30]). The 3D numerical and measured results are judged to be in 
Table 4 Parameter values for base case and sensitivity analyses

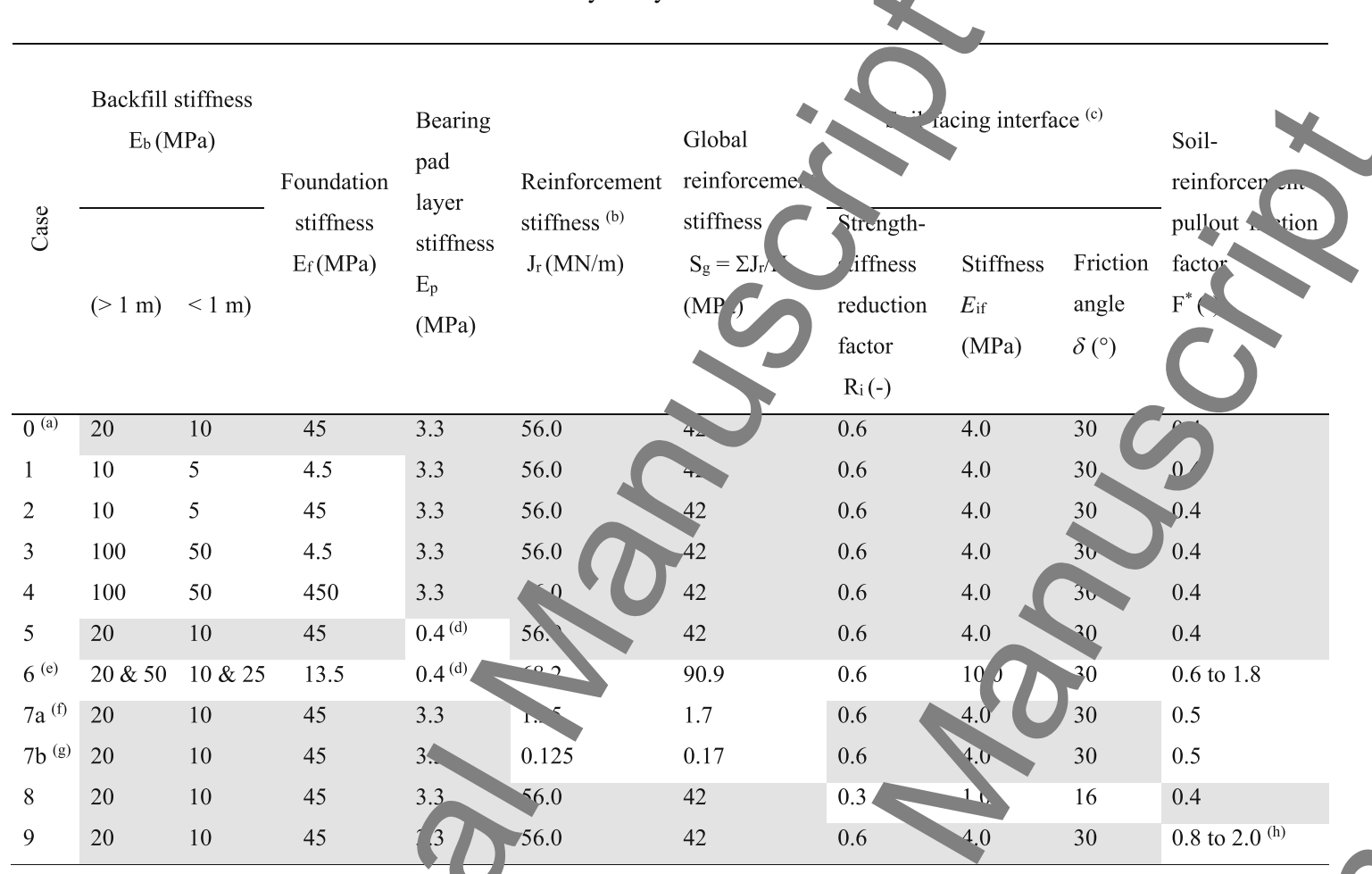

${ }^{a}$ Base case values are shown in sh at cells

${ }^{\mathrm{b}}$ Stiffness based on 1-m runping $\mathrm{cth}$ of the wall with reinforcement strips placed at horizontal spacing of $1 \mathrm{~m}$

${ }^{c}$ Interface reduction factor s mu v viea with shear modulus of adjacent so to compute shear modulus of interface el $\mathrm{m}$ hts $\mathrm{The}$ equivalent

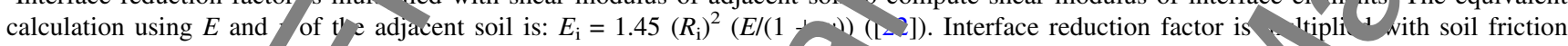
coefficient to compute in re element friction angle as: $\delta=\operatorname{atan}\left(R_{\mathrm{i}}\right.$ and $)$

${ }^{\mathrm{d}}$ EPDM bearing pads [19, 23]

${ }^{\text {e}}$ Values from Yu et al. [49] for PWRI wall case [15]. Wall constrl cted smooth steel strips

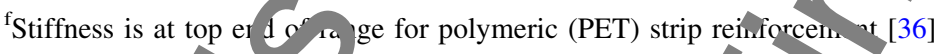

${ }^{\mathrm{g}} \mathrm{Stiffness}$ is at lower end range for polymeric (PET) str $p$ reinfor nent [36]

${ }^{\mathrm{h}}$ AASHTO [1] fo ribbed steel strips

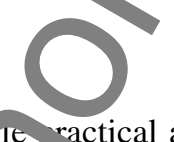

reasona or ractical agreement in the plots in Fig. 3 given the co nlexity of the physical system. Ancreasing the back " elastic modulus from the hase ase value of 20 'Pa to a stiffer value of $50 \mathrm{MPa}$ was judgeu to improve to ov rall agreement between mea red and predicted values in this study using the $3 \mathrm{D} F F^{\prime}$ nowel. Also shown $i 1$ the figure are the 2D numerical $n$ odel 1 sults reported by Yu et al. [49] using the program 다 AN and 2D modelling by the writers using the pro m PLAXIS. These values also appear to do well, bu he in nerical outcomes vary with choice of numerical approch (i.e. FEM code or FDM). It can be concluded th the 3D model does not have practical advantage on he 2D models when comparisons are limite to disadvantage of the, approach is the discontinuous reinforcement strips $\mathrm{n}$,st be treated as continuous elements in the plan strain $(x)$ direction. This poses a challenge for keel/strip walls that are constructed with variable horizon spacing between reinforcement strips in a layer, as in the Mr. now Creek wall in the USA investigated by Runser et al. [45] and Damians et al. [21].

Comput $d$ o and foundation vertical pressures for the PWRI wall using the 3D model are presented in Fig. 4. Founda on pressures were not measured in the physical test. The m asured vertical toe pressure deduced from mea urem nts reported by Chida and Nakagaki [15] is $296 \mathrm{~km}$, which is close to the calculated value of $309 \mathrm{kPa}$ sing we 3D numerical model in the current study. The toe low is greater than the self-weight of the column panels. 1. ratio of these values is the footing load factor comuted as 2.15 and 2.06 for numerical and measured cases, espectively. The difference in toe load and panel self- 


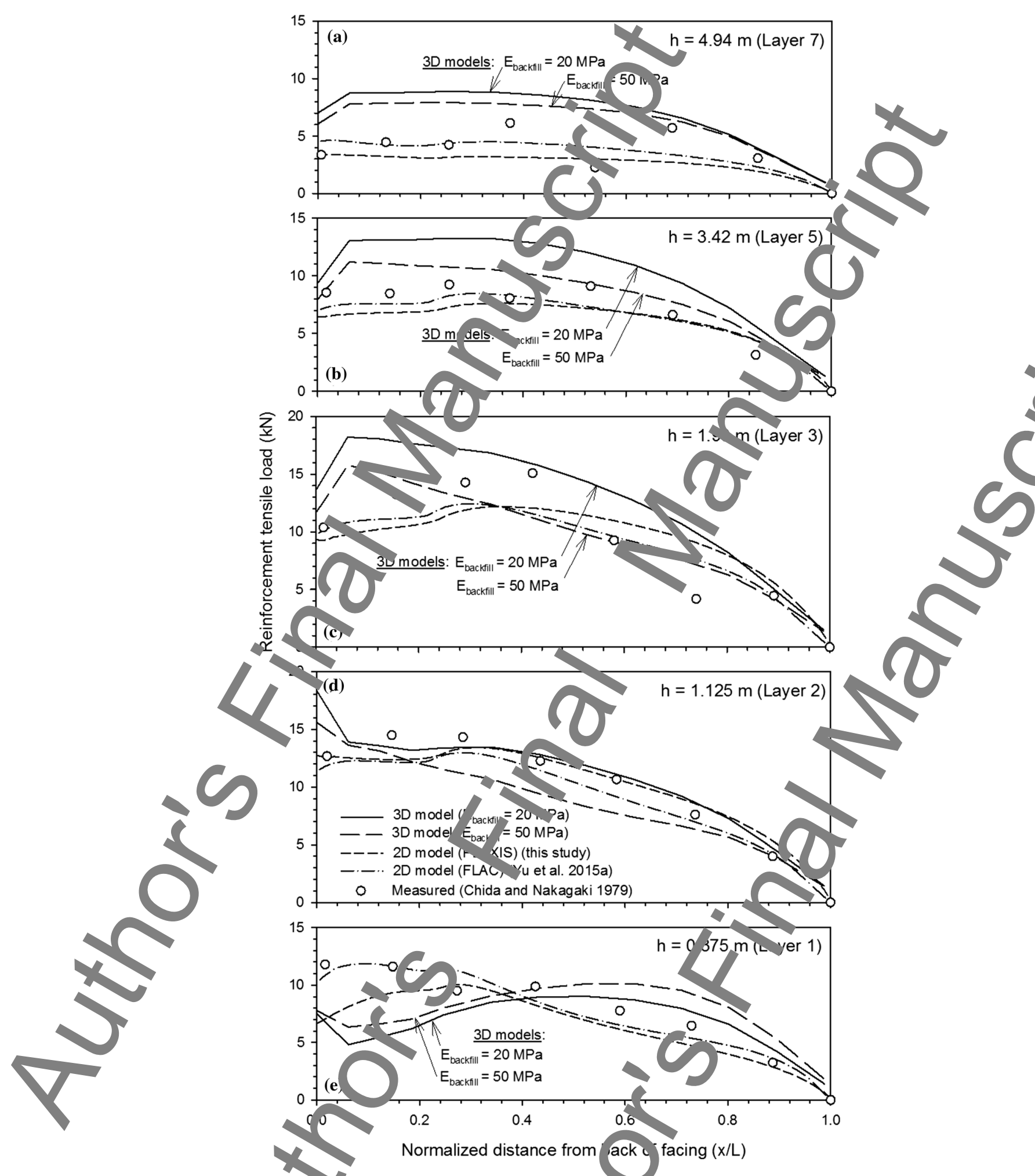

Fig. 3 Measured and predicted to vile reinforcement loads for PWRI wall i rent study and numerical (FLAC) results reported by [49] using Case 6 material properties in Table Note: $h=$ height of layer above toe or we wall

weight is ascribed to th down-drag shear stresses devel- strips as the wall panels move out and the soil behind oped between the pan $1 \mathrm{~s}$ and the reinforced soil, ard ioves down.

hanging up of the reinforced soil on the reinforcement 


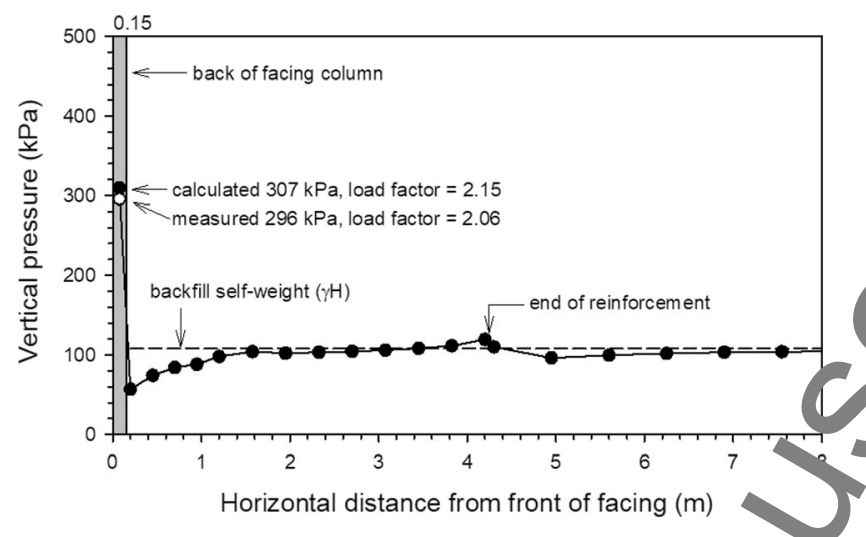

Fig. 4 Toe and foundation vertical pressures for PWRI w 11

\section{Results of base case numerical si n lickions}

\subsection{Example 3D plots}

An important feature of the CODE_BRI UT program is that numerical outcomes can bxtracted easily and visualised using a third-party software ragke. Examples are shown in Fig. 5 and in Figu es or and S2 in the Supplementary Material to this paner.

Figure 5a shows horizont 1 dis lacements in the $z$ direction computed with respec the location of the toe at the end of constructio . The rost deformations of about $5 \mathrm{~mm}$ occur behind he cond panel from the bottom of the wall and dissipate $\mathrm{w}_{\mathrm{m}}$ - distance into the reinforced soil zone. Horizontal deformations at the wall toe and reir forced soil-retaine $A$ fll $^{11}$ boundaries are about $2 \mathrm{~mm}$.

Figure $5 \mathrm{~b}$ how ver cal displacements with re pect the original to Vertical displacements through t e h $\mathrm{h}$ ght of the facing pa els are about 7-8 $\mathrm{mm}$ and are lary due to the comr ress le bearing pads. Within the reinforced soil zone and tain d backfill, the relative vertical deformations ar a $13 \mathrm{~mm}$. The relative downward deformation or he backfill soil behind the facing pamels anticipates dow drag shear forces on the back of t $\mathrm{e}$ ac $\mathrm{ng}$ panels wh h was mentioned earlier for the PWRI wain case and is discuss dater in the paper.

\section{.2 Horizontal displacements}

Figure 6 shows outward disprementeriles for selected wall cases at end of const tion. Wall deformations are small. However, there are dete ble differences in some cases that can be ascribed to th difference in magnitude of properties assigned to ans ar wh wall components. For example, Fig. 6a s owo $\rightarrow$ for the same walls varying only with respect to stiffness of the bearing pads, the wall with softer (EPD $y$ ) bearing pads led to greate. deformations over the top three facing units. Not unexpectedly, he walls with more extensible polymeric strap reinf ICO ent developed greater outward deformation than the se cose steel strip reinforcement case as shown in Fig. 6b. N wever, the difference in out re displacements r polymeric strips bracketing th nge of stiffness deduved from actual polymeric ( $\mathrm{PE}^{\mathrm{T}}$ stra values was not pra tically different. The influenc of 1 terface reduction tactor $\left(R_{\mathrm{i}}=0.6\right.$ and 0.3$)$ was negligible as shown in Fig. 6c. Similarly, changing th mas itude of the interface friction coefficient $F^{*}$ did not have practical influence on wall facing deformations $\left(\Gamma^{\circ} \mathrm{g}\right.$. Ou). From this observation, it may be concluded that $\mathrm{l}$ or perational (working stress) conditions, it is the siciness of the reinforcement that influences wall defomatio is rather than the interfare capacity between soil anu-einforcing strip.

In all cases, the outward displacements are judged to $b$ small enough not to buf practical concern. For exam le, a maximum ou $\mathrm{va}$ d isplacement of $5 \mathrm{~mm}$ for a sal reinforcec oil $\mathrm{ar}$ of $H=6 \mathrm{~m}$ corresponds to a rmalised out arudeformation of $0.08 \%$ of the walr neir at. This i he horizontal toe deformation of a se to $2 \mathrm{~mm}$ whin is thus a large portion of the max mu wall deformation. FHWA [25] provides a chart that hows that for a steel wall of height $H=6 \mathrm{~m}$ and forcement of length $L=0.7 \mathrm{H}$, a first-order approxim a1 for maximum oun ard deformations that may orcur do in construction 15. $1 \mathrm{~mm}$ (or normalised displacem th $0.4 \%$ ). The same hat anticipates maximum outwar deformations of $80 \mathrm{~mm}$ (or normalised displacen nt or $1.3 \%$ ) for extensible reinforced soil walls but makes no specific recommendation for polymeric ap walls. The maximum numerically predicted valu this study is about $8 \mathrm{~mm}$ (or normalised displacement $(f 0.13 \%)$ for the most extensible polymeric strap wall $(\mathrm{C}>7 \mathrm{~b}$, It can be concluded that the walls in this study e wen within deformation limits expected of producian molls at end of construction and under operatior al condituns.

In real-wo ases, the magnitude of wall outward displacements and al wall alignment is strongly influenced by construction quality and technique. Hence, the quantitative or a mes reported here must be appreciated in relative rams xamples of the significant influence of construc ion technique on facing alignment can be found in the paners by Allen and Bathurst [4] for an 11-m-high mod ilar ock wall reinforced with geogrids and a steel strip in orced 17-m-high incremental concrete panel wall 1 epond by Runser [44] and Runser et al. [45]. Numerical m delling of these walls by $\mathrm{Yu}$ et al. [52] and Damians a [21] was not able to explicitly account for the effects f documented construction issues in their numerical simlations. Most often the challenge during construction is to maintain the target wall facing batter by making local 


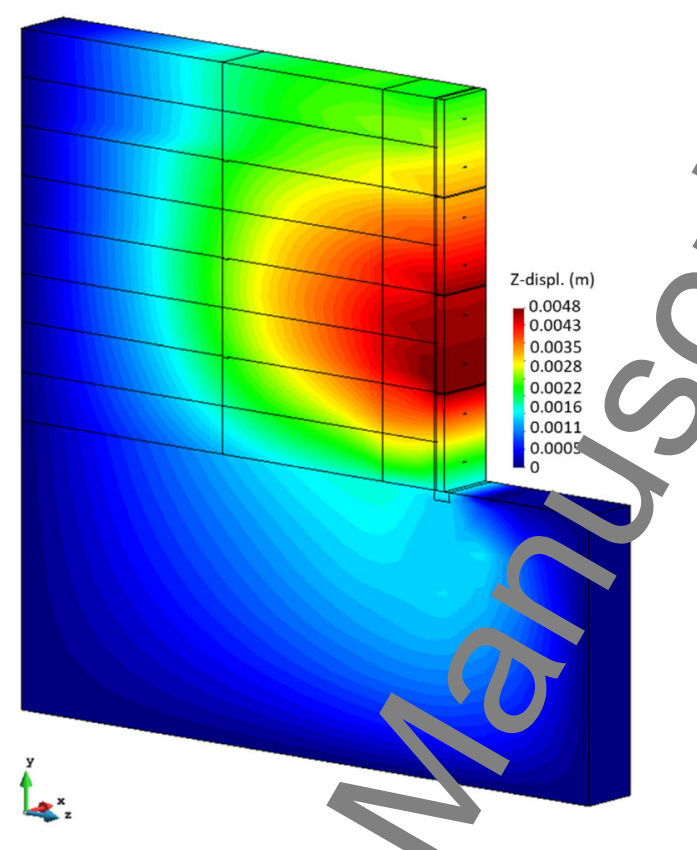

(a) horizontal displacements (ni)

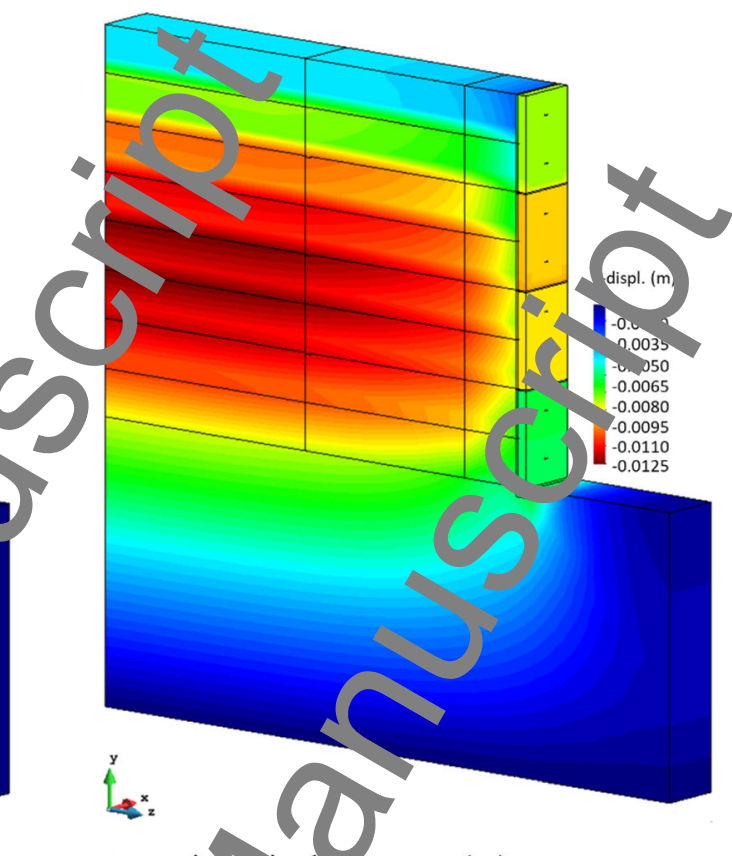

(b) vertica a. placements $(\mathrm{m})$

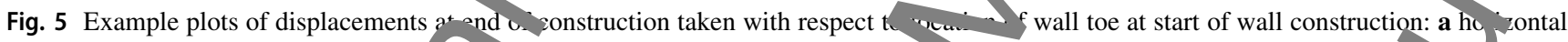
and $\mathbf{b}$ vertical. (Case 0 - steel strip w: 1)

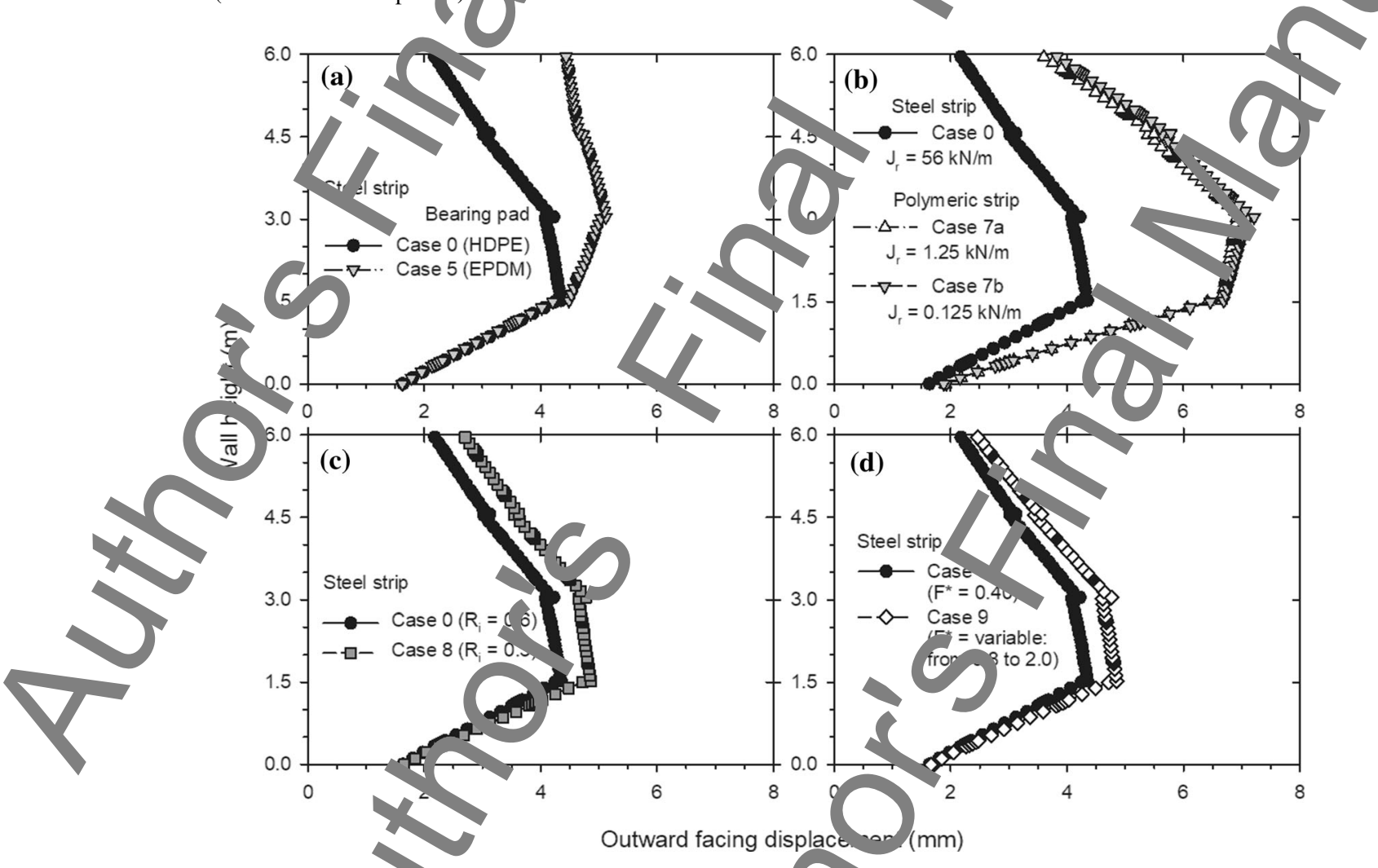

Fig. 6 Outward facing displa -ments with respect to original toe of wan start of construction

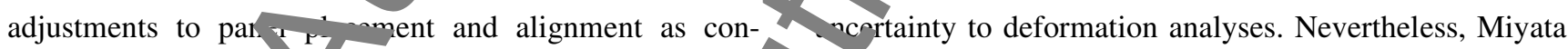
struction proceeds.

The moving datum to monitoring points used to trac $0-190 \mathrm{~mm}(0.1-2.9 \%$ of wall height) from monitored wall facing deformation measurements in the fie polymeric strap walls of similar height to the wall in this 
study. The numerical models in the current study for the polymeric strap case gave $0.13 \%$ of the wall height and thus fall just inside the lower range of values available from field measurements.

The reinforced soil mass may also experience a competing backward rotation when seated on a compliant (compressible) foundation [19, 31]. This can be appreciated by the larger vertical displacements located within the reinforced soil zone in Fig. 5b compared to the front of th wall.

Figure 7 shows facing displacement profiles compun for different combinations of backfill and four ation modulus values. As the foundation modulus beco ans and all other parameter values remain unchar oed, the horizontal deformation of the wall increas For the weakest backfill and foundation soil combina or (c ase 1), the wall has the appearance of rotating

Horizontal displacement profiles taken at the sace and at selected distances from the face are porm Fig. 8 for the base case (Case 0). The plots in this nure show that outward deflections are greatest the face but decrease with distance from the face of the warm

\subsection{Reinforcement layer vertic ettlements}

Figure 9 shows vertica» settm ment profiles for selected layers using steel and $r$ lymen strips. The datum for these plots is the elevatio of he wall toe at start of wall construction. The settlemen increase with distance from the facing and are greater for the more extensible polymeri strip material. Th $c$ difference is a maximum of $a b o$ $2 \mathrm{~mm}$. For ea $\mathrm{c}$ c. in each plot, the smallest sett emen are close to connections, which is consis ant hanging up on the soil over the reinforcemen strips described a antu

\subsection{Re .... vrcement loads}

Fig 10 suows reinforcement load distril ut on along the lent $r_{c}^{\text {th }}$ or selected reinforcement layers. The fuar curves in each $\mathrm{p}$ ot correspond to different cor binations of reinforcu soil and foundation soil modulus. vverall stiffness 4 tre soil materials increases in tl e ord $r$ of Case 1,2,3 and 4 as identified in Table 4. In oenu, the magnitude of rinforcement tensile loads eases in the reverse order when all other parameters nam unchanged. The exception occurs close to the connea with the facing particularly at the bottom-most layo (e.g. Layer 2 in Fig. 10). An explanation for this is $\mathrm{r} r$ atively low stiffness of the backfill soil located wr.. $1 \mathrm{~m}$ of the facing.

An important obsc ation from this figure is that the maximum tensile loads re greatest in the vicinity of the connections for the two stiffest reinforced soil cor

\section{S}

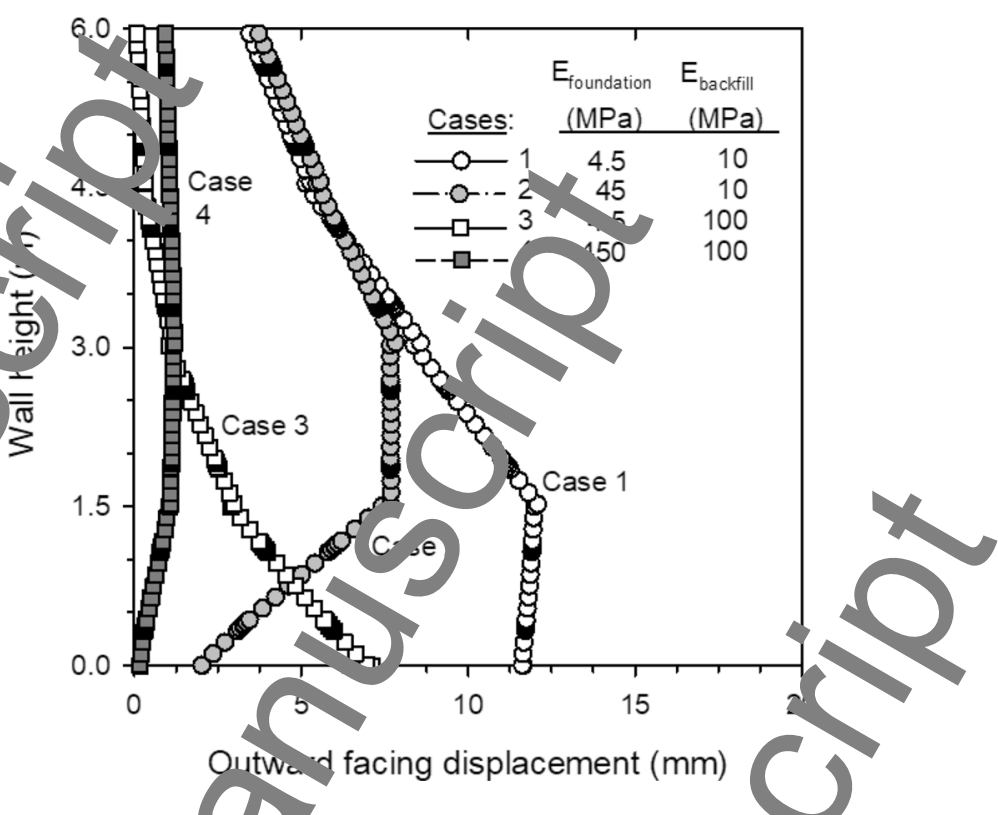

Fig. 7 Outyard inc ig isplacement profiles at end of cor auction (Cases 1, 2, 4 ,

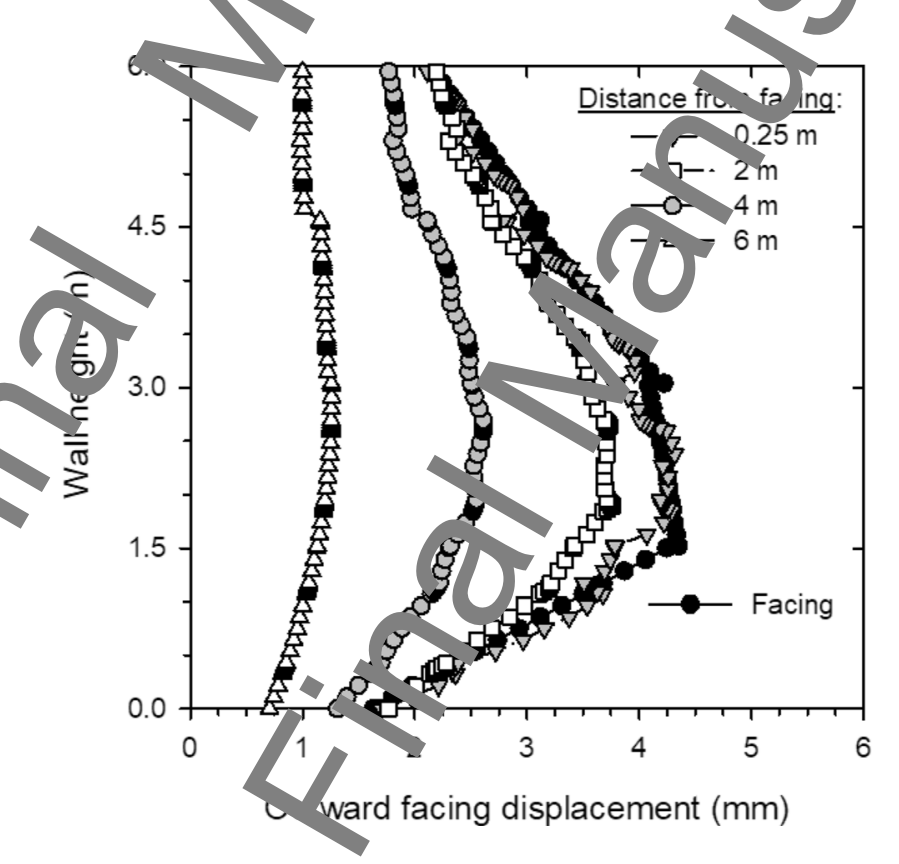

Fig. 8 Outward displacement profiles at face of wall to $6 \mathrm{~m}$ from facing at end of $c$ truction (Case 0)

$\rightarrow 2$

while fo the softer soil conditions the peak tensile load is located anser to the middle of reinforcement length. An impl cat 1 for design is that the maximum tensile load shou $d$ als $\delta$ be applied at the connections to be conservat vas safe. This assumption is made in North American sign codes for all MSE walls [1, 18], while in other codes (e.g. 111]; AFNOR [3]) the tensile load at the connections may be taken as some fraction of the computed maximum insile load depending on the flexibility of the facing and the connection system. 


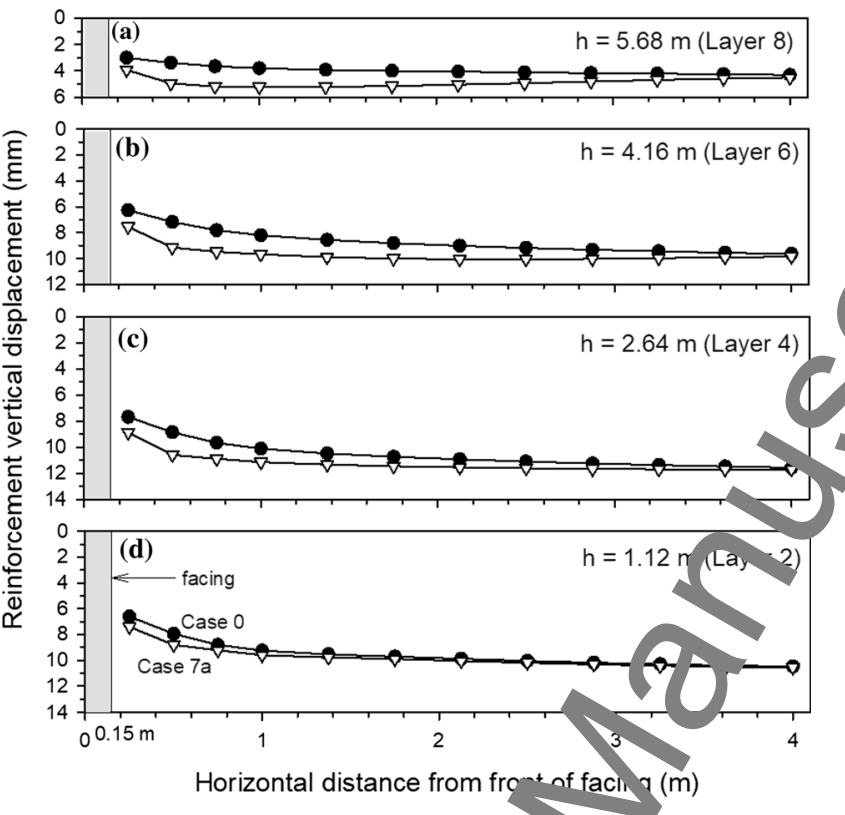

Fig. 9 Vertical settlement profiles for selected sul (Case 0) and polymeric strip reinforcement layers $(C-7 a)$ at end of construction

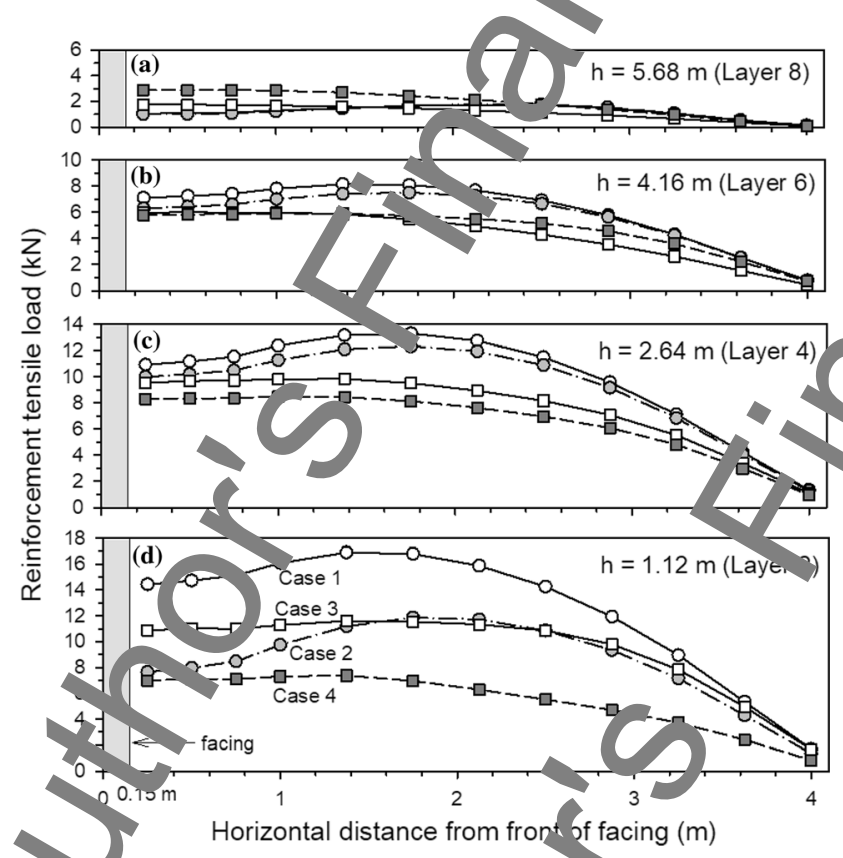

10 Tensile reinforcement loads in se ecte reinforcement layers or Cases 1, 2, 3 and 4 showing influenc of fol hdation and backfill soil modulus

In this study, numerical nula ions were carried out to investigate the influence of bean pad compressibility on wall performance. Results rela do reinforcement tensile loads are shown in Fig. 1 jenerally, maximum reinforcement loads a rwa with the softer bearing pad arrangement (Case 5). F arthermore, for the softer bearing pad configuration the ma imum reinforcement loads are an the connections. The larger tensile loads for the ctar bearing pad configuration are consistent with the larger facing un armations for this wall compared to the same wall sur vith stiffer bearing pads (Fig. 6a). However, this relat e formance difference may not occur for other coln inat ns of soil modulus and reik cement stiffness at were not examined in this study

The influence of reinforcement iffne $s$ on reinforceme t loads is shown in Fig. 12. ma, he expected, the reinforcement loads are much igher for the steel strip einforced wall in compariso with the otherwise nominally identical two cases wi a stif ness values associated with more compliant PET rap walls. The stiffness of the two PET strap cases vari $c y$ factor of 10 , but the difference in loads varies hv kus than a factor of 2 . The difference in peak reinforce ment loads between steel and the stiffest PET stra - asu 1 a factor of 70 , but the ratio maximum loads i abou 10. The nonlinear increase it reinforcement loads vith reinforcement stiffness $s$ in sympathy wit (t) e raalitative trend using the stiffin based $\operatorname{sim}$ ified ti iness method developed by A ler and Bathurst [5, 1 is method has been recently adopted oy

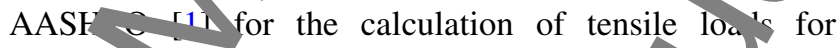
internal stu ility of MSE walls constructed wh cosynthetic reinforcement materials.

Similar sensitivity analysis comparisolm were carried sout to isolate the influence of the str ng and stiffness reu ction factor on reinforced loads (Case 8 and 9). These a ${ }^{1}$ vses showed no practical diffe en meinforcement bar magnitude and distribution and th s are not presented.

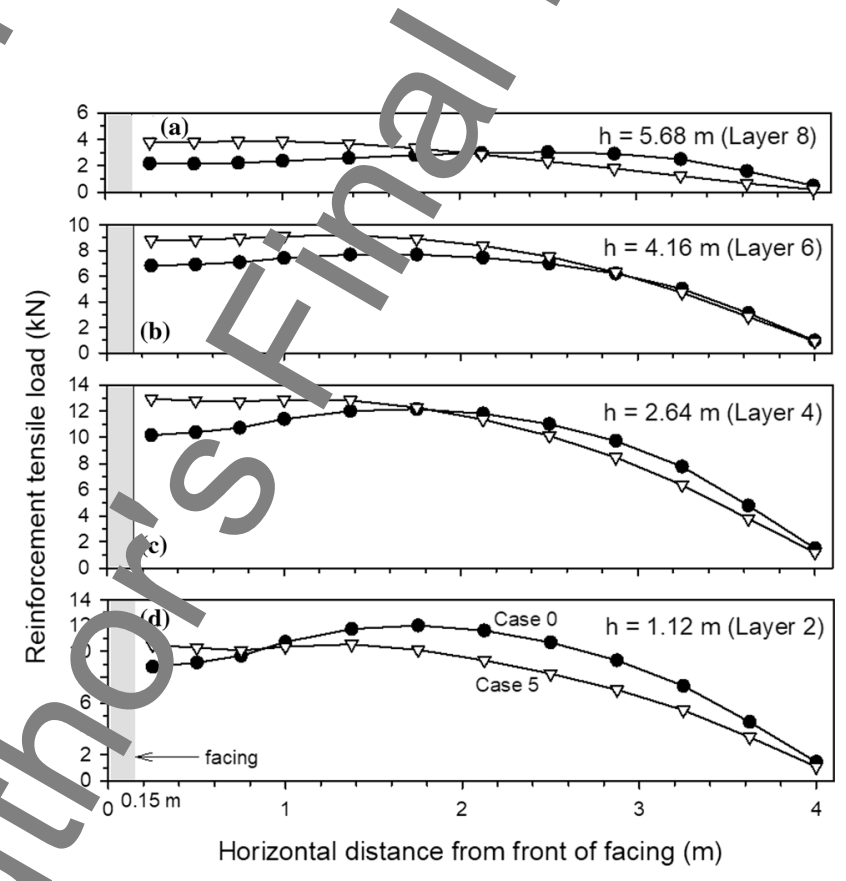

ig. 11 Tensile reinforcement loads in selected reinforcement layers for Cases 0 and 5 (relatively stiff and soft bearing pads, respectively) 


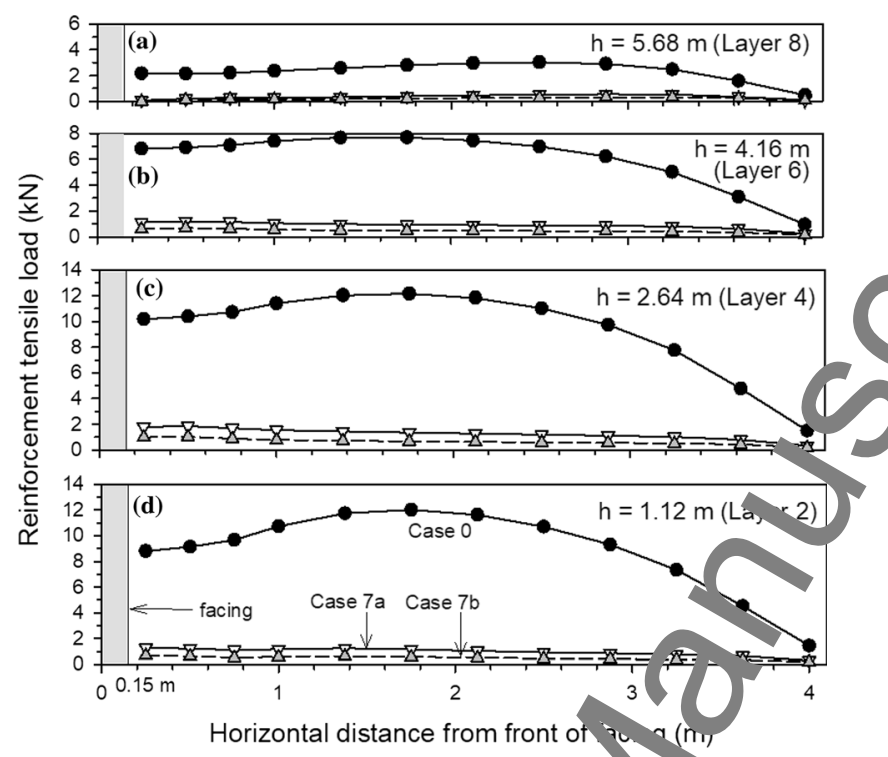

Fig. 12 Tensile reinforcement loads in sele layers for Case 0 (relatively stiff steel reinforcement), nd Cases 7a and 7b (relatively less stiff PET strap reinforcement)

\section{Earth pressures}

\subsection{Vertical foundation pr cur}

Figure 13a shows the con wten wertical foundation pressures and the vertical pressure exerted by the facing column on the footing fo th base case (steel strip). Data with solid symbols are located wectly at the midlocation of the wall below the centreline of the steel strips. The data poin s with open symbol $\mathrm{re} \mathrm{ec}$ that the toe load pressures varr in the running lents th diction of the wall. This sma threedimensional ef ect cannot be detected using a $20 \mathrm{~m}$ del. The distributions of foundation pressure corresponan to the same tl ree lo ations were not practically detectable and for this reas are not plotted to avoid visual clutter. As discoss $\mathrm{d}$ to the PWRI wall, the vertical toe pressure is greater $n$ the pressure due to self-weigh of the column panels i footing load factor $>1$ ) w doy $n$-drag on the $\mathrm{ba}^{\mathrm{k}}$ of the concrete panels and on he steel strips. The Io. fo tors are 2.82, 2.72 and 2.64 to noints located at $0105 \mathrm{~m}$ from the lateral boundar es, niapoint between ateral boundary and steel strip, a d d rectly below the entreline of the steel strips, re potively.

Figure 13b shows the found ion pressures for the same case above but using the les, tiff pulymeric reinforcement (Case 7a). The foundatin pressures are essentially unchanged, but the vertical to pressures are less at the same locations along the rumming length of the wall. The load factors are no $2 \rho \delta, 2.47$ and 2.41 at the same locations as above. Fr $\mathrm{m}$ a practical point of view, the differences between the two reinforcement cases with respect to the down-drag loads are not significant but they are detur. ble

$\mathrm{Fi}$ JIr $13 \mathrm{C}$ shows the results of calculations using other conn natir ns of soil elastic modulus for the steel strip case. For he ca of very stiff soil properties ase 4), there is a - lativery large reduction in vertical toressure compared to thu other cases including Case o How ver, qualitative trer ds in the distribution of foun tion ressures remain unchanged.

Finally, the computed loa facm in Fig. 13a-c are typical for measured values epory $d$ in the literature for field walls [19] and mostoften fall within the recommended range of 2-3 for af ae gn of the bearing pads for incremental concrete par walls in the USA [25].

\subsection{Vertical presc...res $\ldots$ and in the vicinity of the reinfe rcemment strips}

A major moti ati on cor the numerical simulations in hic study wa to it ve tigate 3D behaviour which ca be expected to e a ferent from an equivalent 2D walr mo el. Figure hat s vertical pressure distributions con puted at $0.25 \mathrm{~m} \mathrm{sm}$ the front of the facing panels. $\mathrm{Nots}$ in the figure show that:

1. Close to the facing, the vertical prescures a a height of $2.5 \mathrm{~cm}$ above the strips are greate th an the soil selfmight at this location. At cm be the strips, vertical pressures are attenuated ab one-half those at $2.5 \mathrm{~cm}$ above the strip planation for this behaviour is that the block on soil behind the wall facing wants to move ${ }^{-}$own with respect to the wall face as the facing movo outward and the soil compresses. The rei fo a pent strip impedes this movement, and the soi h ngs up on the strip. The soil located betwe n th strips then imparts down-drag forces on the oil $1_{1}$ umn above the strip. This results in greater $n$ mal wess on top of the strip than soil at the same levo ion and located on either side of the strip.

2. The vertical pressures directly below the strips decreas with decreasing distance from the strip and are les an the constant pressure recorded beyond abor $20 \mathrm{~cm}$ of the strip centre at the same elevation. It show d be noted that a small amount of soil cohesion - $\mathrm{kra}$ in Table 1) was used in the model to avoid umer cal instability at the free boundaries. This -esulted in very small negative vertical stresses directly below the reinforcement strips as shown in Fig. 14. Nom a practical point of view, these stresses should be assumed as zero.

The lateral distance over which vertical pressures close to the back of the facing panel are modified by the steel 


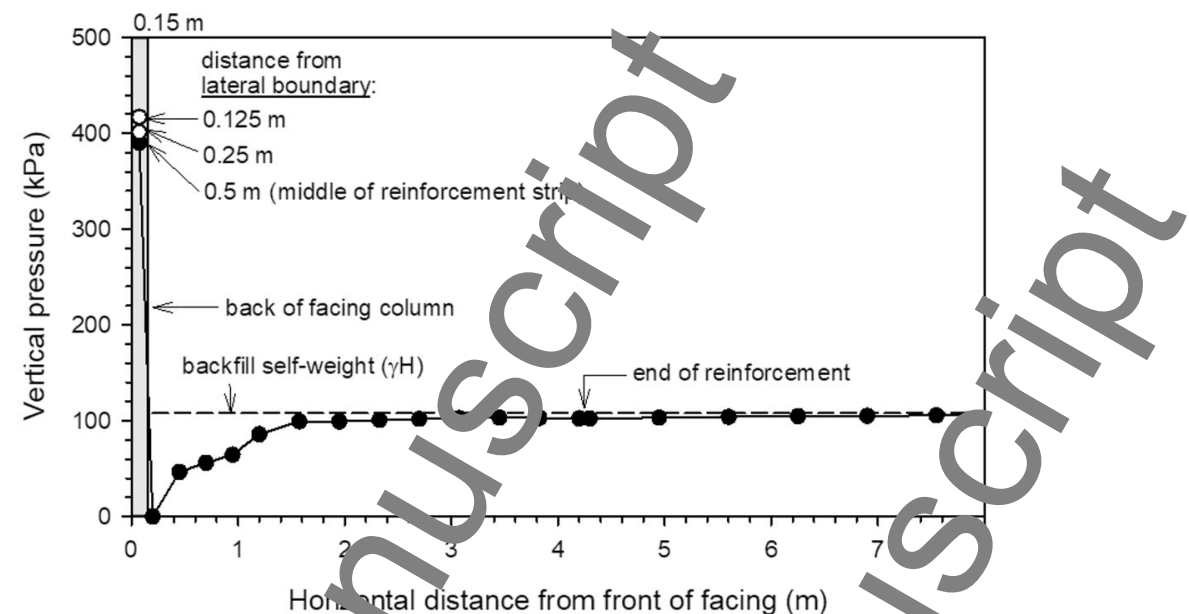

(a) Base Case $c(\mathrm{~s}$, eel reinforcement)
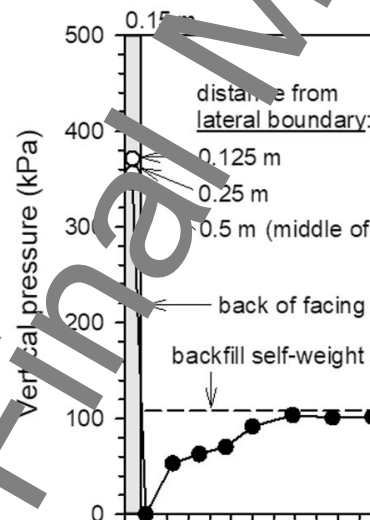

$0.125 \mathrm{~m}$

$30.11 \quad 0.25 \mathrm{~m}$ (middle of reinforcement strip)

back of facing column

backfill self-weight $(\gamma \mathrm{H})$

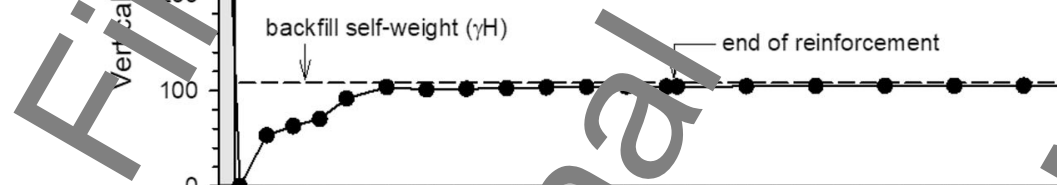

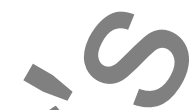
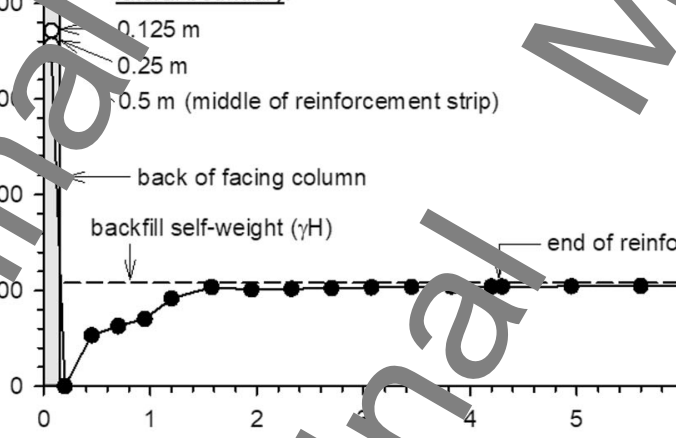

(b) Case 7a (polymeric wir,

Horizental u tance from front of facing $(m)$

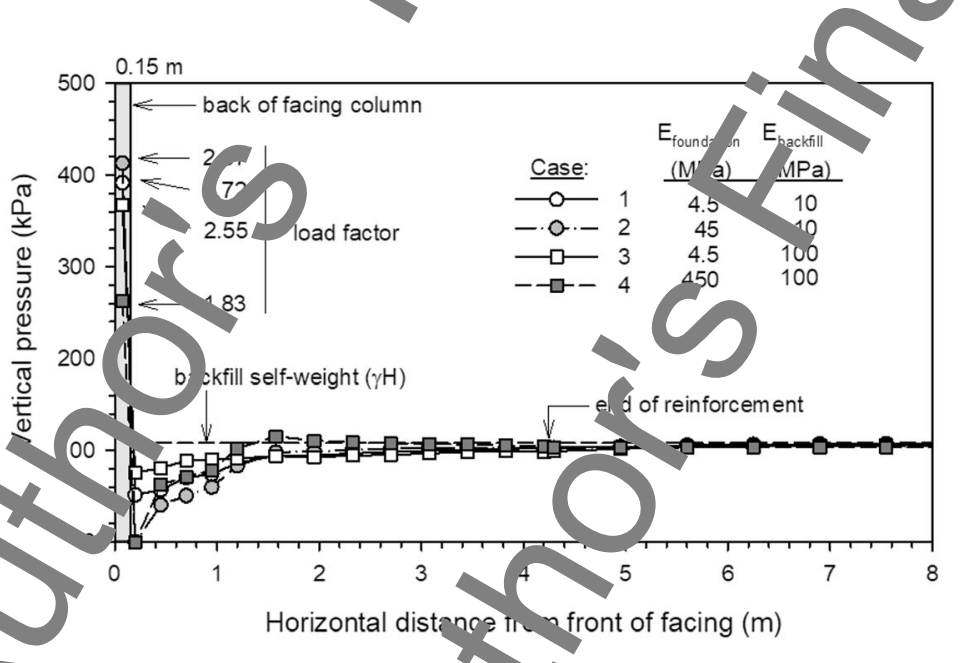

(c) Cases 1, 2, 3 and 4. Pressures dir tly bu..ow the centreline of the steel strip reinforcement strips

Fig. 13 Vertical foundation pressures at end of construction

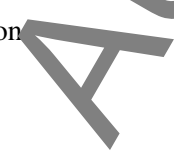




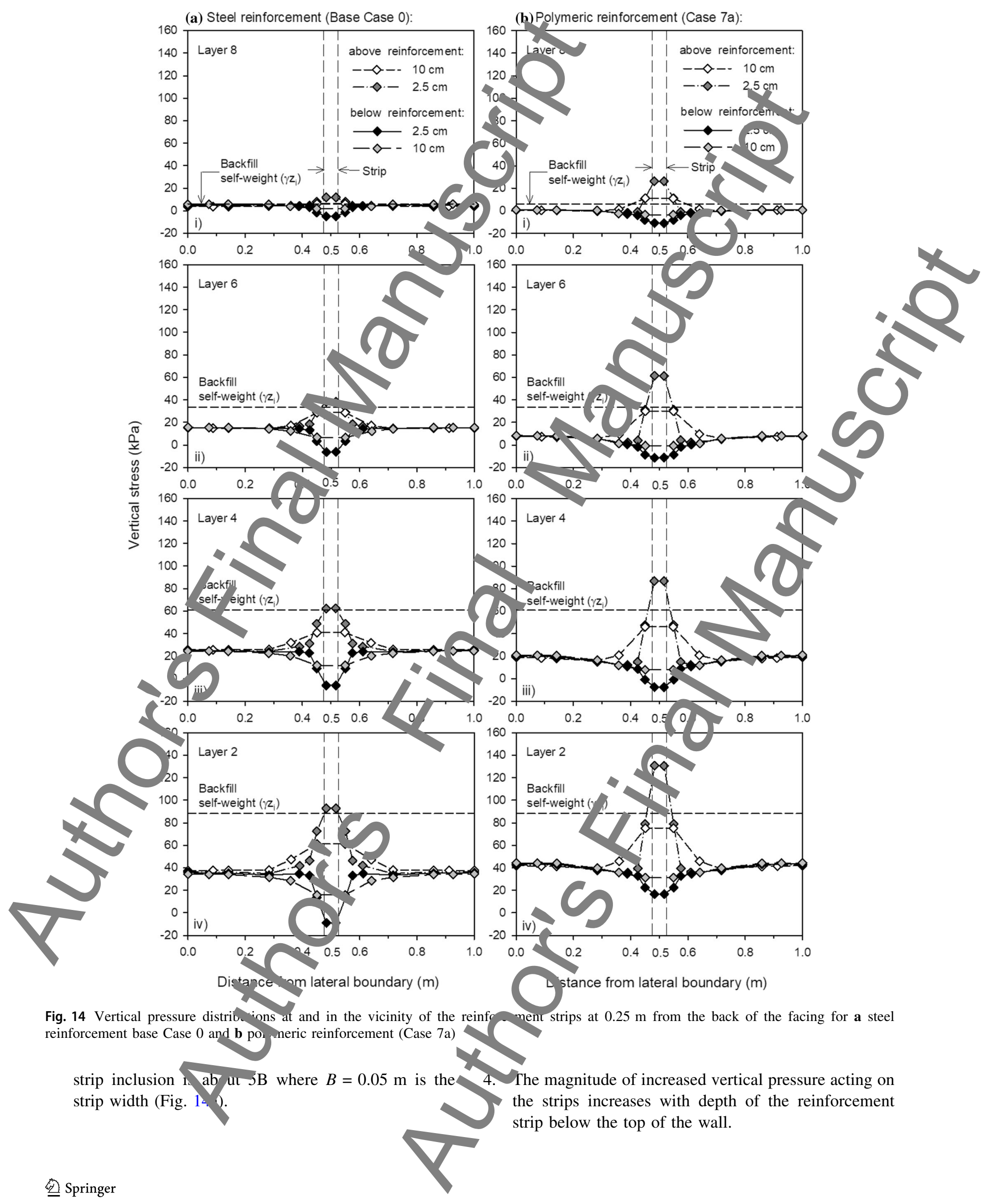




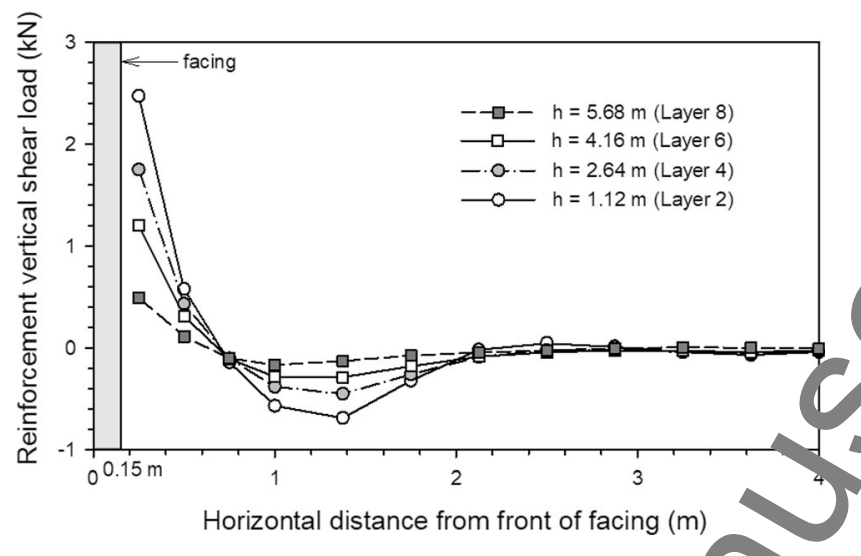

Fig. 15 Vertical shear load along length of steel strip re forcement layers (Case 0)

5. The maximum vertical pressure actin on $\mathrm{La}$ er 2 close to the back of the facing is about a fa to of 2 and 3 greater than the pressure beyond ' adg of the steel and polymeric reinforcement layers, spectively.

6. Qualitative features are the same for steel and polymeric cases. However, Layes of the stiffer steel strip wall has slightly lower $\mathrm{n}$ ax -1m vertical pressure above the strip than the matchi g olymeric strap. For the topmost Layer 8, the $r$ ory neric strap carries greater vertical pressure as well. The larger vertical pressure is consistent with the zrean setuement computed for the polymer strip re ifor ed wall compared to the steel reinforcement caso ig. 9).

The increase in vertical pressure acting over the strip close to the back o th acing column is consistent wh th hanging up of he soll o the reinforcement strips th theat. to the foundati on pressure attenuation immediate $y$ be lind the facing that as described earlier. A practical holication of the obse vations made above is that the over-pressure acting $n$ tb strips can be used to check against shear failure $\mathrm{CH}_{\mathrm{i}}$ id connectors between the reinforcement strips and pa. 1 s. For example, Fig. 15 shows a lot of vertical shean ad through the steel strips for the b. cas example with fixed connection. The maximum shear loads are at the con lections as expected, but the 10 ding is well below the connection shear capacity. Def ations of the steel rips at the connections due to con ectio type can also be investigated (e.g. rigidly fixed nncuror or a connector with rotational degree of free $1 \mathrm{~m}$ ).

Figure S3 in the Supplo entar Material for this paper shows similar plots to Fig. 14 tan 7 at $2.0 \mathrm{~m}$ from the front of the facing. At this location, $t$ pressure distributions are almost flat, indicating that ${ }^{\text {th }}$ interference of the reinforcement strips on rerty .... essures above and below the strip elevations has la dy dissipated at this location.

\subsection{Lateral earth pressures}

Figu To shows the horizontal earth pressures acting at the $\mathrm{ck} \mathrm{o}$ the facing in the reinforcement direction and in the all rection at the centreline le.tion of the steel inforcement strips. Sharp jumps cr observed in the pressure profiles against the facing wen ymbols). These pre sures are larger just above the $n$ or he reinforcement strip compared to just below. Th s behaviour is consistent vith the larger and smaller vericar ressures at the same location in Fig. 14. The cor espor ling profile (Fig. 16b) taken through the same he ort or the wall but at the midpoint between the strip ce at dit e and the lateral boundary can be seen to be smootm. Tris is because the disturbance to the earth pressure distrib tion due to the reinforcement inclusions is attmated with distance from reinforcement.

The same quolitats trends can be seen for the nore extensible pol $\mathrm{m}$ in strip reinforcement in Fig. 160, d However, pre res against the wall are lower th or the less exto 'sio steel reinforcement strip cases. In $f . c t$, the $\mathrm{pr}$ locations between and beyond the rymediate influs ce of the reinforcement layers are y, nis dly in the vicinity of $K_{\mathrm{a}}$ values or less. For the ste 1 str. case, the pressures in those same locations are mos often greater than the $K_{\mathrm{a}}$ value and often in the vicini $8 K_{\text {values. The }}$ low $r$ pressures for the polymeric strip ase compared to to - relatively inextensible steel stri a a a in sympathy (it) classical notions of earth nressur theory that predict lower earth pressures with great lateral deformations.

Also shown in the plots of Fig. 10 are lateral pressures (solid grey symbols) at tho same location but in the orthogonal direction (i.e. he ranning direction of the wall face-direction $x$ in is . 1). For the steel strip cases, the orthogonal pressure re most often similar in magnitude to those acting rainst the facing. However, for the matching case with nore xtensible polymeric strips, the orthogonal pre sure are nost often greater and by a relatively large an,$c$ at some locations.

In conventional a. lytical design approaches to compute earth pressures acting against the facing, the out-of-plane soil stresse ca $\mathrm{t}$ be considered. However, frictional soils are stress-leve ependent and ignoring the larger lateral stresses computed in the out-of-plane direction in $3 \mathrm{D}$ numericar odels will underestimate the mean confining stre $s$ in $\mathrm{t}$ e soil, thus making the soil appear weaker and less $s$. iff The recommendation to include the out-of-plane ress $\left(\tau_{x}\right)$ in the calculation of the bulk modulus in nonIIm ar constitutive models for frictional soils has been made Huang et al. [29] and Yu et al. [51, 52] to improve the ccuracy of numerical models for reinforced soil walls with ontinuous sheet reinforcement.

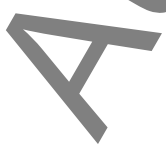




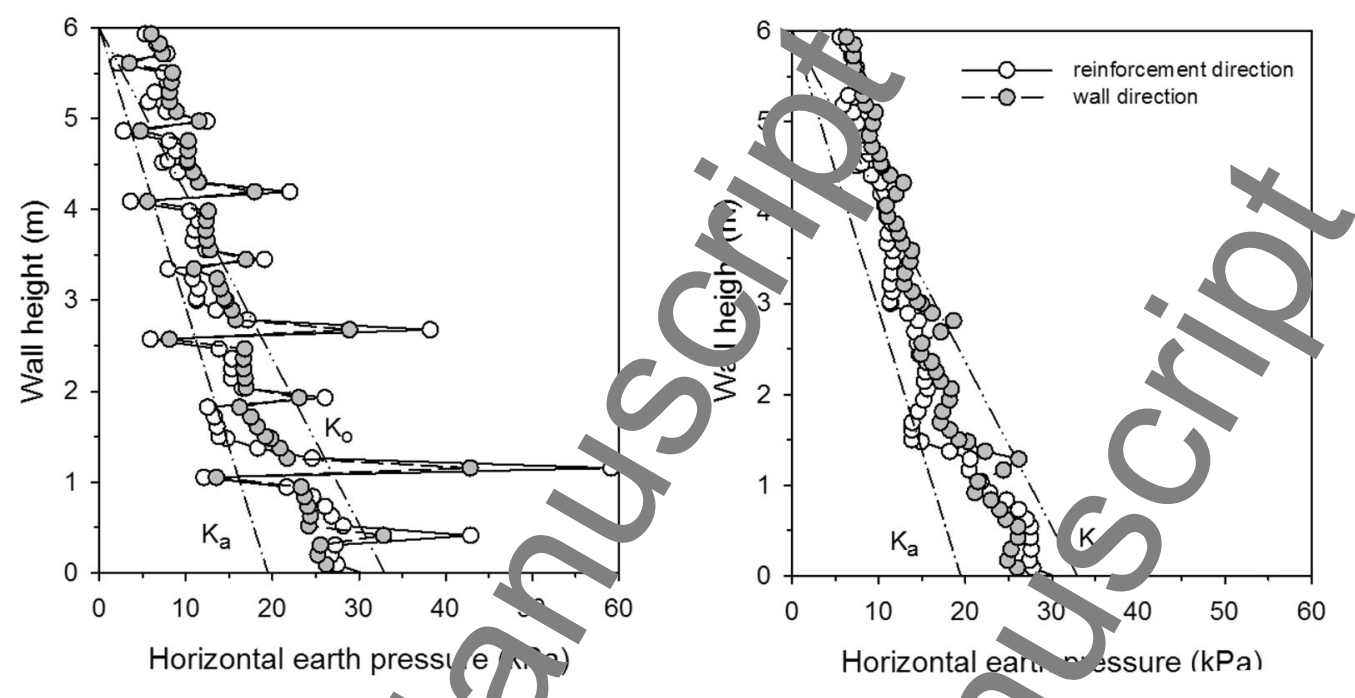

(a) at centreline of reinfor nent er (steel strip - Case 0)

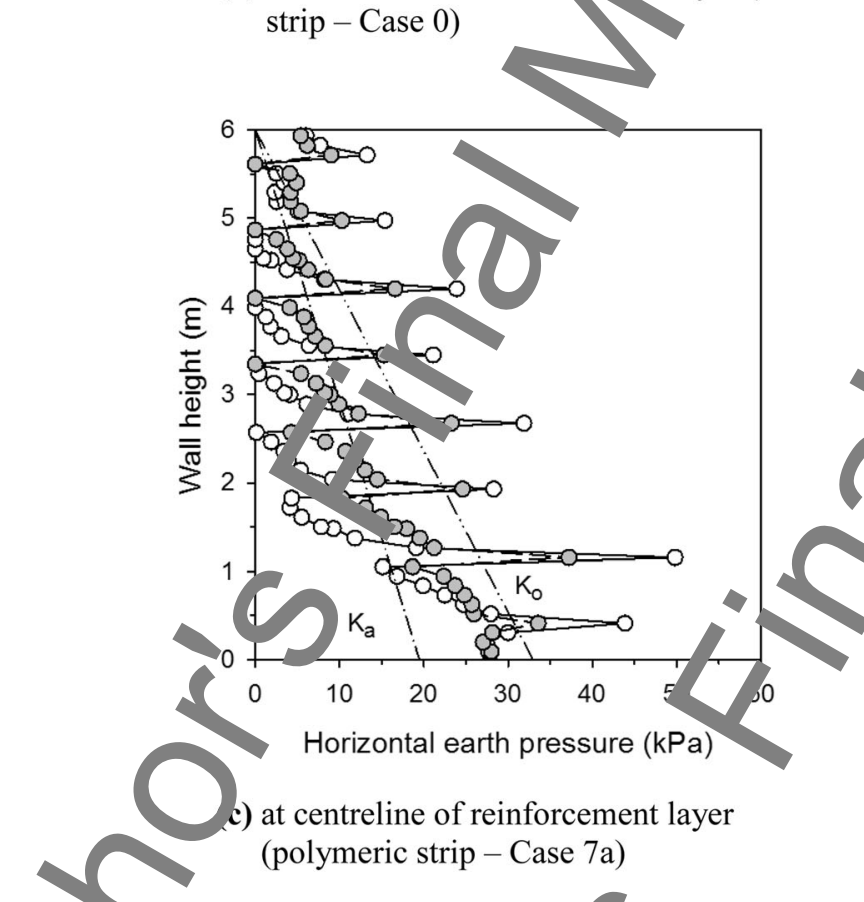

(b) at midpoint $\mathrm{h}$ tween reinforcement layer and lateral houn ry (steel strip - Case 0)
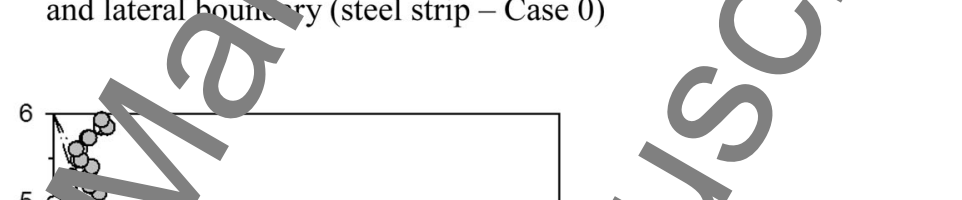

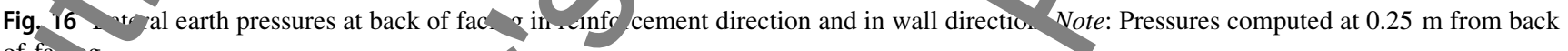
of fau $\mathrm{o}$

\section{Cunclusions}

This paper reports the first atsamp to carry out 3D numerical modelling of a tah ( $\mathrm{f}-\mathrm{m}$-hrsh) vertical slice of a MSE wall constructed with eel ip reinforcement since the work of Ho and Smith [28]. 3D model was used to predict the influence of reinto sement type on wall performance using the exam of relatively inextensible (steel strip) and ratry extensible (polymeric strip) materials that are co mon components in MSE walls constructed today.
The pap rd instrates that the 3D model does not have practicaradvant ge over simple 2D models for walls with simple $\mathrm{r}$ inforcement arrangements and no surface loading when coln arisons are limited to tensile reinforcement load and areful attention is paid to choice of parameters for th 1 , strip reinforcement and the facing parameters. I ow or, the advantage of the general 3D model approach 1s hat the influence of the discrete reinforcement strips on umerical predictions of the magnitude and distribution of ressures acting on the wall facing and on the steel strips is etectable. This is not possible using $2 \mathrm{D}$ continuous reinforcement sheet approximations to rows of discrete 
reinforcement strips as is the approach used most often today. The ability to model the MSE wall components in 3D holds promise to better predict the tensile loads in the reinforcement strips/straps (particularly when reinforcement strips are placed at variable spacing in a layer), evaluate stresses in the facing panels (Figure S4) and compute shear loads at the connections. These advantages can assist to avoid over-stressing at these locations and to optimise wall design. However, the connection details the numerical models used in this study are purposely ke simple. Connection performance predictions can expected to change as model details at the location $f$ the connections are improved.

A disadvantage of the modelling approach in is paper is that computational demands are large, at leac or typical high-end desktop computers that are curren ly av rlable. However, this is expected to be less of rob. 1 in the future. Hence, this study holds promise to pr viu guidance to designers for taller and more corn reinforced MSE walls as 3D numerical modelling software suitable for MSE wall structures impres and computational power increases.

Acknowledgements The authors wish to ck owledge the support of the International Center for $\mathrm{Nu}$ al Methods in Engineering (CIMNE) and the funding rece ed from the Spanish Ministry of Economy and Competitivenes thro oh the "Severo Ochoa Programme for Centres of E cellenco in R\&D” (CEX2018-000797-S), and the Natural Sciens $s$ ar Engineering Research Council of Canada (NSERC) (Grant iber: 94344-2013).

References

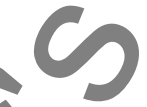

1. AASHTO (2 20) AASHTO LRFD Bridge design sp ific? Ions, 9th Ed. Am ican Association of State Highway an transportation ials. Washington, DC., USA

2. Abdelou ab A, Dias D, Freitag N (2011) Numerical analysis of the behan on of mechanically stabilized earth walls reinforced with alm ent types of strips. Geotext Geomembr 29(2):116-129

3. Ar DR (Association Française de Normolisation) (2009) otecm jeal design-Retaining structures- eir or ed and soil nailm tructures. NFP 94-270. Paris: A VOn

4. A. n TM, Bathurst RJ (2014) Performanc of a $11 \mathrm{~m}$ high block-

face $\mathrm{r}$ geogrid wall designed using the $\mathrm{K}$ tiffness Method. Can Outech J 51(1):16-29

Men TM, Bathurst RJ (2015) An i nprove l simplified method for prediction of loads in reinforced se ${ }^{\prime} \mathrm{wa}^{1} \mathrm{~s}$. ASCE J Geotechn Geoenviron Eng 141(11):040150

6. Allen TM, Bathurst RJ (20 Application of the Simplified Stiffness Method to desig re, forced soil walls. ASCE J Geotechn Geoenviron Eng 144-04918024

7. Allen TM, Bathurst RJ (201, Geosynthetic reinforcement stiffness characterization for MS 1 wall design. Geosynth Int 26(6):592-610

8. Bathurst RJ, Miy a probabilistic assessm $t \mathrm{t}$, margins of safety for internal stability of as-built PET strap inforced soil walls. Geotex Geomembr (availabe online). https://doi.org/10.1016/j.geotexmem.2020.06. 0012

9. Bouroeors 2, Soyez L, Le Kouby A (2011) Experimental and $\mathrm{n}$ imeric 1 study of the behavior of a reinforced-earth wall subjo ted t a local load. Comput Geotech 38(4):515-525

10. ourg is E, Le Kouby A, Soyez L (2012 nfluence of the stripbackill interaction model in the analycic of th behavior of a nechanically stabilized earth wall. So s Fou d 52(3):550-561

11. BSI (2010) BS8006-1:2010 + 1:20 co of practice for trengthened/reinforced soil and otho fills. CI, Milton Keynes

. Cai Z, Bathurst RJ (1995) Seismi response analysis of geosynthetic reinforced soil segmental retan ing walls by finite element method. Comput Geotech 17( ):523 546

13. Capilleri PP, Ferraiolo F, Mo E, cotto M, Todaro M (2019) Static and dynamic analys of two mechanically stabilized earth walls. Geosynth Int 26(1) $26+1$

14. CODE_BRIGHT User' Guid 2016) Department of Civil and Environmental Engineerins Barcelona School of Civil Enoineering, Universitat 1 itècr ca de Catalunya (UPC) and Inter national Center for merrcal Methods in Engineering (CIMNE https://deca.upc.e/ u/ca/endepartament/seccions/etcg/recerca/pro jectes/code_bright ttps://www.gidhome.com/gid-plus/mo ales/ modules-rese rcr 7 /codebright/

15. Chida S, Nal gg ki I (1979) Test and experiment on a fi-1-scar model ainfo earth wall. In Proceedings of in ern al conferenc or ail reinforcement, Paris, vol II, pp 533- 338

16. Ch fani C, Wu P, Gagnon G, Macintosh M (2011) precast facea nechancal stabilized earth solution for $a^{\infty} 0$ met e high mining cru her wall with various technical and site chum nges. In Proceedings of 2011 Pan-Am Canadian geote hnica sonference (CD-ROM), Canadian Geotechnical Society, Richmond, BC, Canada, 625

Cristelo N, Félix C, Lopes ML, Dias M 20 6) Monitoring and In nerical modelling of an instrume ad me ha ically stabilised arth wall. Geosynth Int 23(1):48-61

iSA (2019) Canadian Standards Assoc ation (CSA). Canadian Highway Bridge Design Code. AIv'-S6-19, Mississauga,

Ontario, Canada

19. Damians IP, Bathurst RJ, Josa A, Lloret A, Albuquerque PJR (2013) Vertical facing loads in el reinforced soil walls. ASCE J Geotech Geoenviron Eng 1 120 ):14^-1432

20. Damians IP, Bathurst RJ Jo a Lloret A (2014) Numerical study of the influence of fo nd tion compressibility and reinforcement stiffness on ne havior of reinforced soil walls. Int $\mathrm{J}$ Geotech Eng 8(3):24 259

21. Damians IP, Bathu $\mathrm{t}$, Josa A, Lloret A (2015) Numerical analysis of an istrumen steel reinforced soil wall. ASCE Int J Geomech 15 1):0 014037

22. Damians IP, Y, Lloret A, Bathurst RJ, Josa A (2015b) Equivalent interfaco properties to model soil-facing interactions with zero-thickness and continuum element methodologies. In: XV Pan- me an conference on soil mechanics and geotechnical ngin ang XV PCSMGE), from fundamentals to applications in gevechnics. Buenos Aires, Argentina. 15th-18th Nove nber 2015, pp 1065-1072

23. Damiarm IP, Bathurst RJ, Josa A, Lloret A (2016) Vertical facing p mel- int gap analysis for steel-reinforced soil walls. ASCE Int Geom ch 16(4):04015103

$24-$ Fan $C$ (2006) Three-dimensional behaviour of a reinforced ear retaining structure within a valley. Comput Geotech 33(2):69-85

5. FrHWA (2009) Design of mechanically stabilized earth walls and reinforced slopes. In: Berg RR, Christopher BR, Samtani NC (eds) No. FHWA-NHI-10-024 Vol I and NHI-10-025 Vol II, Federal Highway Administration, Washington, DC., USA

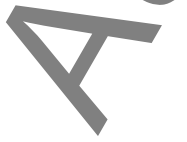


26. Hatami K, Bathurst RJ (2006) Numerical model for reinforced soil segmental walls under surcharge loading. ASCE J Geotech Geoenviron Eng 132(6):673-684

27. Hatami K, Bathurst RJ (2005) Development and verification of a numerical model for the analysis of geosynthetic reinforced soil segmental walls under working stress conditions. Can Geotech J 42(4):1066-1085

28. Ho DKH, Smith IM (1991) Modelling of reinforced soil wall: construction by a 3-D finite element method. Paper P4/6. In: McGown A, Yeo K, Andrawes KZ (eds) Performance of reinforced soil structures. Thomas Telford Publishing, Londo pp 335-340

29. Huang B, Bathurst RJ, Hatami K (2009) Numerical study of reinforced soil segmental walls using three different constitutiv soil models. ASCE $\mathrm{J}$ Geotech Geoenviron Eng 135(10):1486-1498

30. Itasca (2011) FLAC: Fast Lagrangian Analysis of Contma. Version 7.0. Itasca Consulting Group, Inc., Minneapu MN, USA

31. Jones CJFP, Edwards LW (1980) Reinforced art $\mathrm{s}$ ructures situated on soft foundations. Geotechnique $20: 20-13$

32. Karpurapu RG, Bathurst RJ (1995) Behavio, O. reosynthetic reinforced soil retaining walls using th finite c 'ement method. Comput Geotech 17(3):279-299

33. Kulhawy FH, Mayne PW (1990) Manual o estimating soil properties for foundation design. RG art EL-6800, Electric Power Research Institute (EPRI). Palo Alto, Ca fornia, p 306

34. Ling HI, Leshchinsky D (2003) Fi all lement parametric study of the behavior of segmental $\mathrm{b}$ oc $\mathrm{r}$ inforced-soil retaining walls. Geosynth Int 10(3):77-94

35. Lo SCR (1998) Pull-out res tano of polyester straps at low overburden stress. Geosynth 5(4):361-382

36. Miyata Y, Bathurst RJ Ain Tm (2018) Evaluation of tensile load model accuracy for PET Drap MSE walls. Geosynth Int 25(6):656-671

37. Miyata Y, Bathurst RJ, Yen TM (2019) Calibration of PET strap pullout models using a ratistical approach. Geosynth In 26(4):413-427

38. Naylor DJ, Ricl ard (1978) Slipping strip analysis of reinforced eartk Int ${ }_{1}$ Num $r$ Anal Meth Geomech 2(4):34 -366

39. Olivella S, Cens A, Carrera J, Alonso EE (1996) Jum tical formulation a r a simulator (CODE_BRIGHT) for in upled analysis of calinu nedia. Eng Comput 13(7):87-112

40. PLAXIS (2008 Reference Manual, 2D: Version 9.02. PLAXIS B.V., De \& Un versity of Technology, Netherlands (http://www.
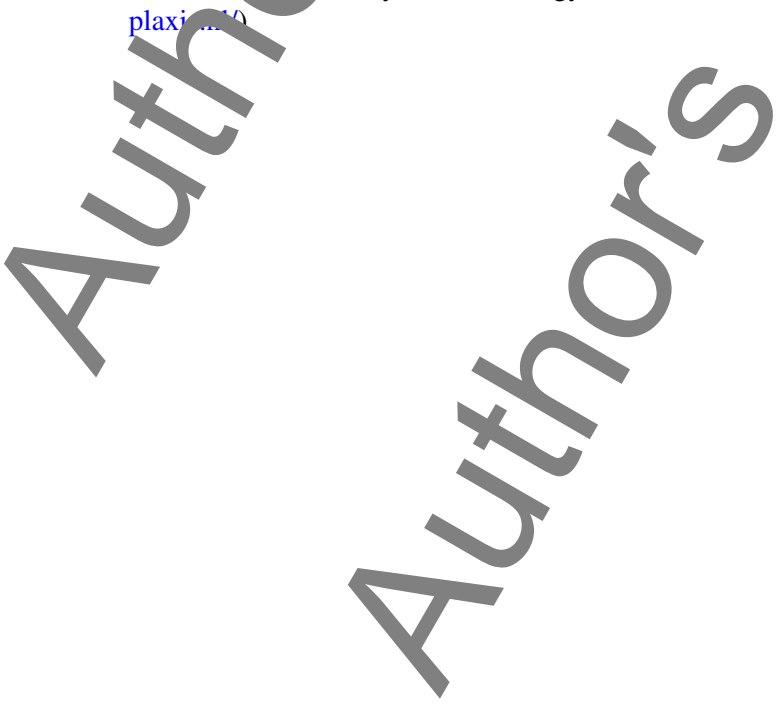

41. PLAXIS (2012) Material Models Manual. PLAXIS B.V., Delft Uni sity of Technology, Netherlands

42. Rowe RK, lo S (1997) Continuous panel reinforced soil walls on r gid undations. ASCE J Geotechn Geoenviron Eng 1. ?(10) )12-920

43. owe K, Skinner GD (2001) Numeric analysis of geosynthet reinforced retaining wall construnted o. a layered soil oundation. Geotex Geomembr 19(7):? 37-4

44. Runser DJ (1999) $17 \mathrm{~m}$ tall reinf cea $\mathrm{rth}$ taining wall. M.S. hesis, School of Civil Engineering, Pura University, West Lafayette, Indiana, USA

5. Runser DJ, Fox PJ, Bourdeau PI (2a1) Field performance of a $17 \mathrm{~m}$-high reinforced soil retair ng wall. Geosynth Int 8(5):367-391

46. Siemens GA, Bathurst RJ, nyata Y (2018) Numerical simulation and parametric analysis $f$ all -anchor walls using the finite element method. Trans Geot 15:57-69

47. Yoo C, Kim SB (2008) Po 'rrmance of a two-tier geosynthetic reinforced segmental aini g wall under a surcharge load: full scale load test and fintte element analysis. Geotext Geomem 26(6):460-472

48. Yoo C, Jang YS, Pa JJ (2011) Internal stability of geosynt'eticreinforced $S$ all alls in tiered configuration. Geosy Int 18(2):74-83

49. Yu Y, hurst D, Miyata Y (2015) Numerical ana ysi co a mechanic. 'ly abilized earth wall reinforced with stecr str $p s$. Soi Found $5(3): 536-547$

50. Yu Damrans IP, Bathurst RJ (2015) Influenc of ch pice of FLAC an 'LAXIS interface models on reinforeed son. iructure interactions. Comput Geotech 65:164-174

51. Yu Y, Bathurst RJ, Allen TM, Nelson R (2u Ghysical and numerical modelling of a geogrid reinforce remuntal concrete panel retaining wall. Can Geotech J 53(1 ): 1 38. - 1901

52. Y Y, Bathurst RJ, Allen TM (2016 ' R-18 geogrid reinforced modular blo $k$ aining walls. ASCE J Feotech Geoenviron Eng 142(5):040160 13

Zevgolis IE (2018) A finite elo amt tigation on displacements of reinforced soil walls under effect of typical traffic loads. Transp Infrastruct Geotechnol 5(3):231-249

Publisher's Note Springer Nat at emains neutral with regard to jurisdictional claims in publisl $d \mathrm{~d}$ na $\mathrm{s}$ and institutional affiliations.

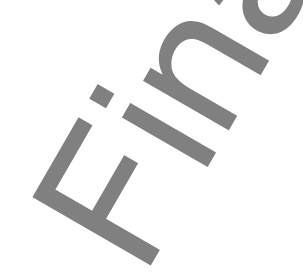

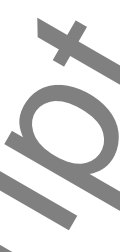
. . . 


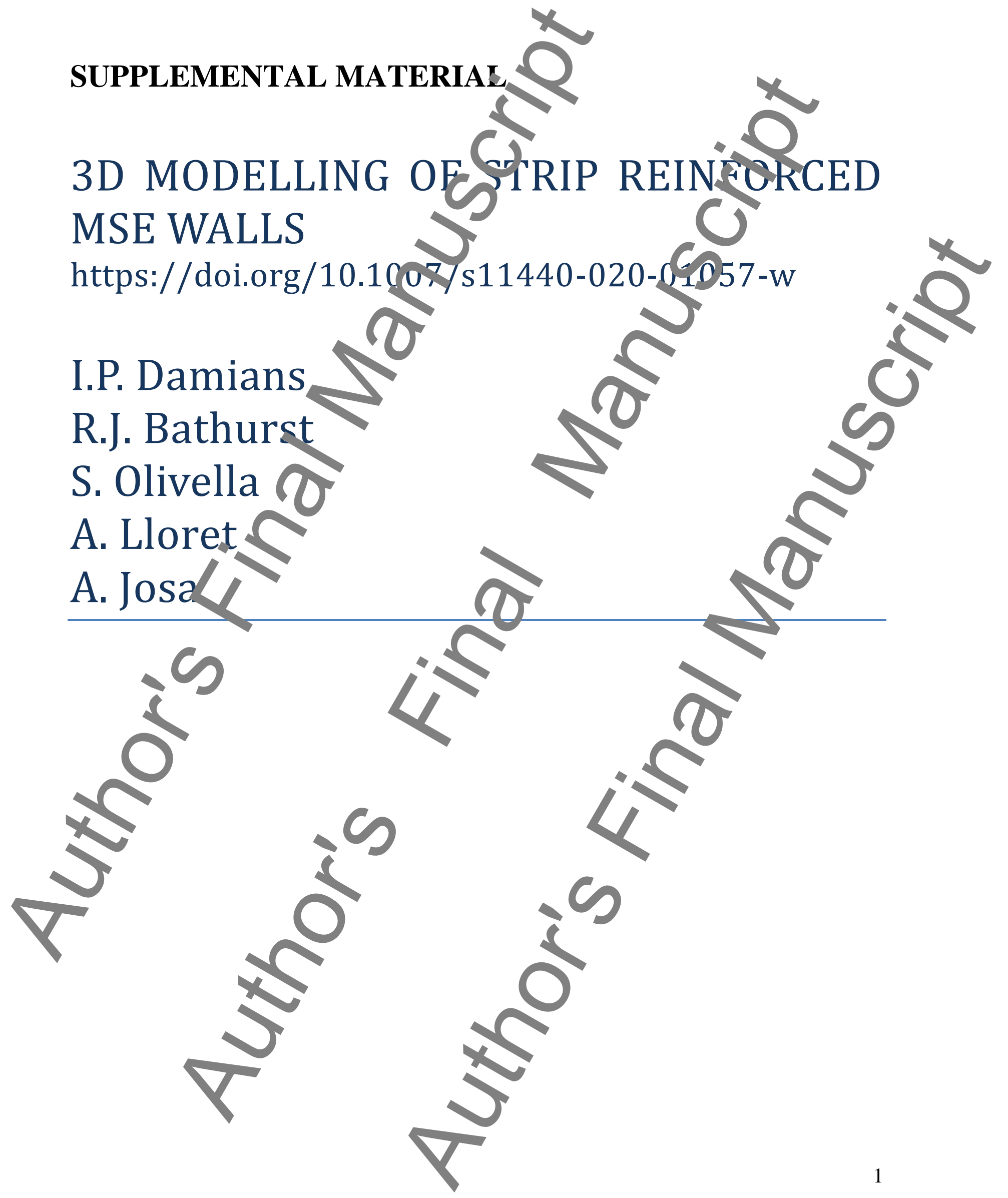




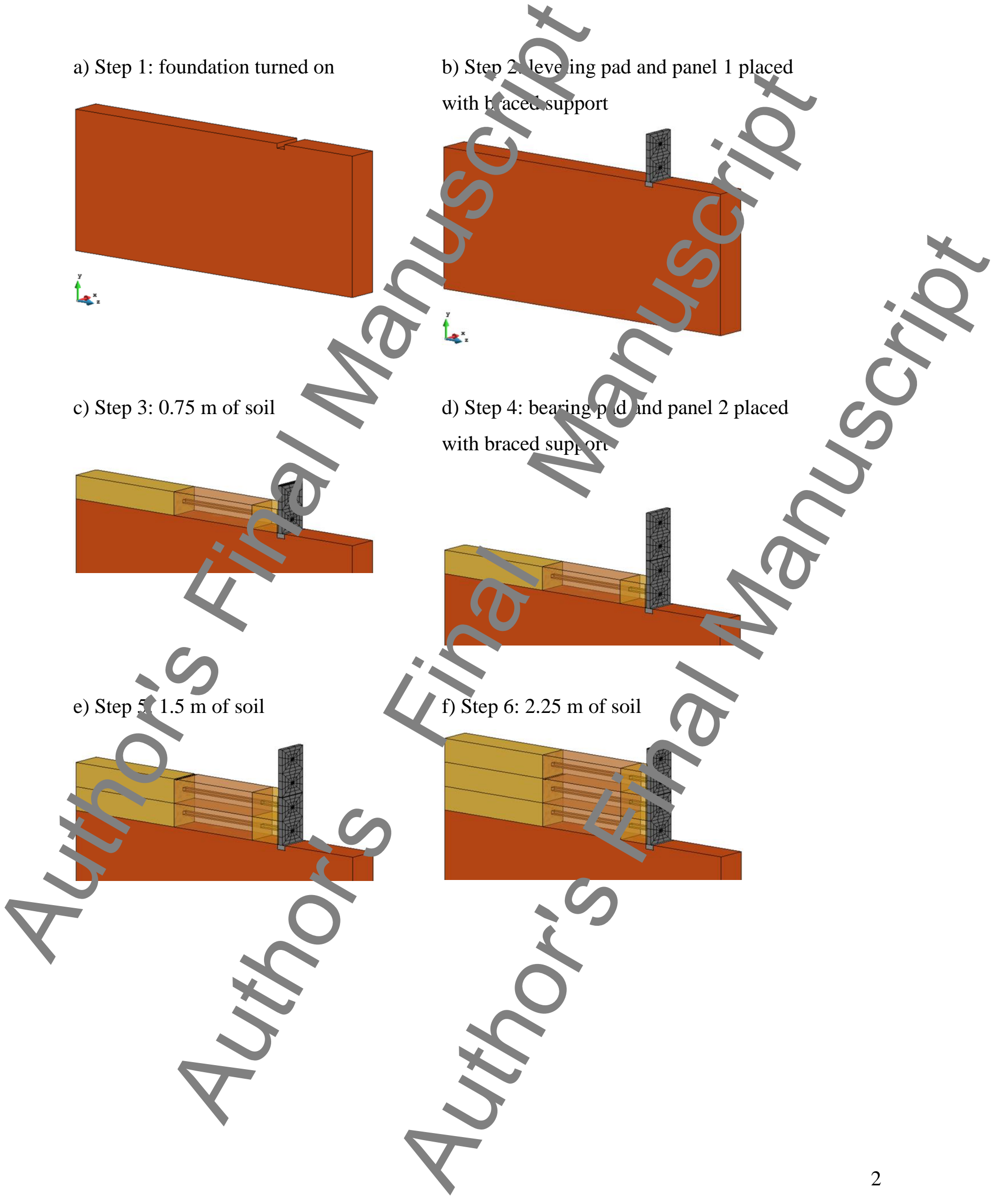




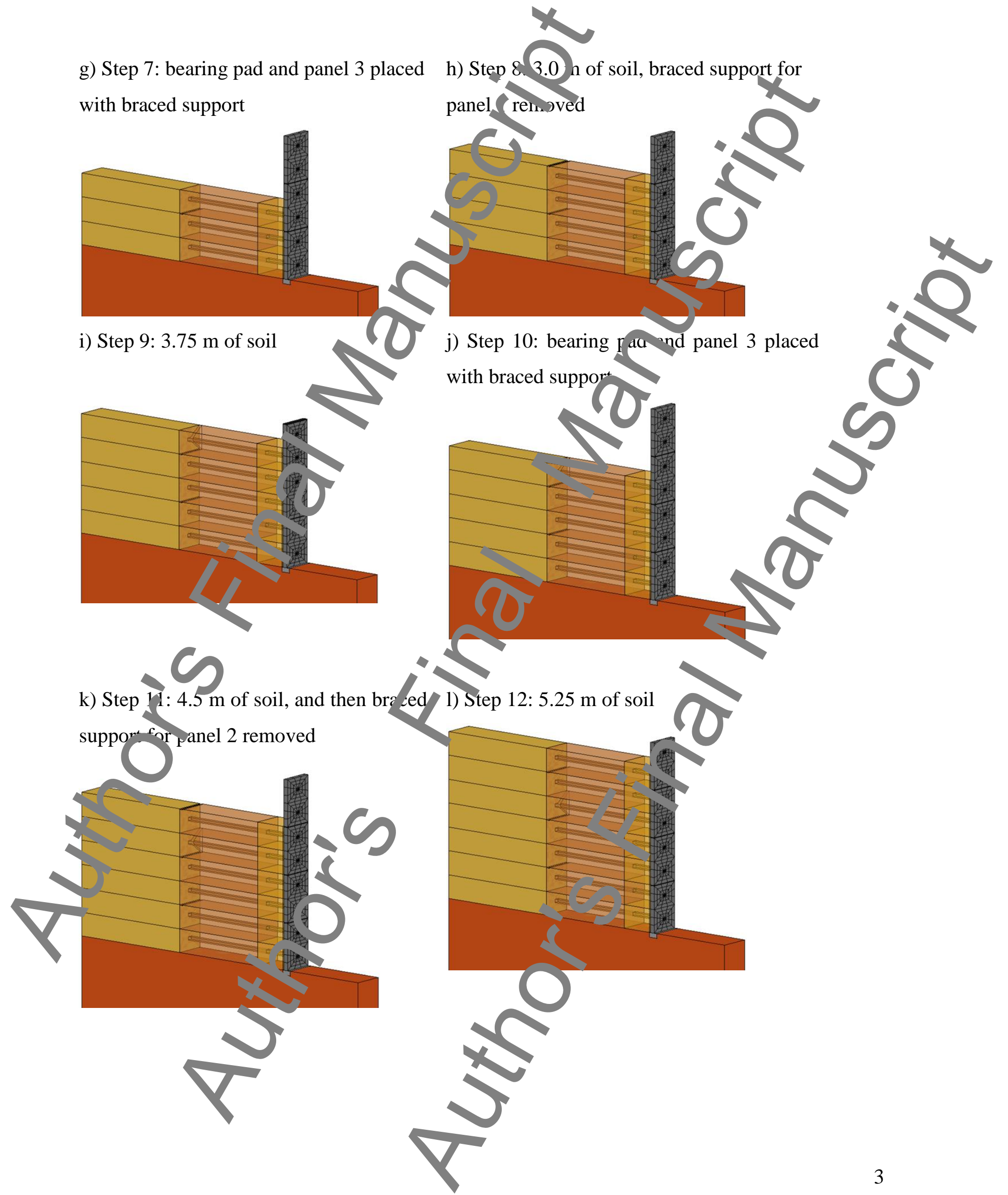




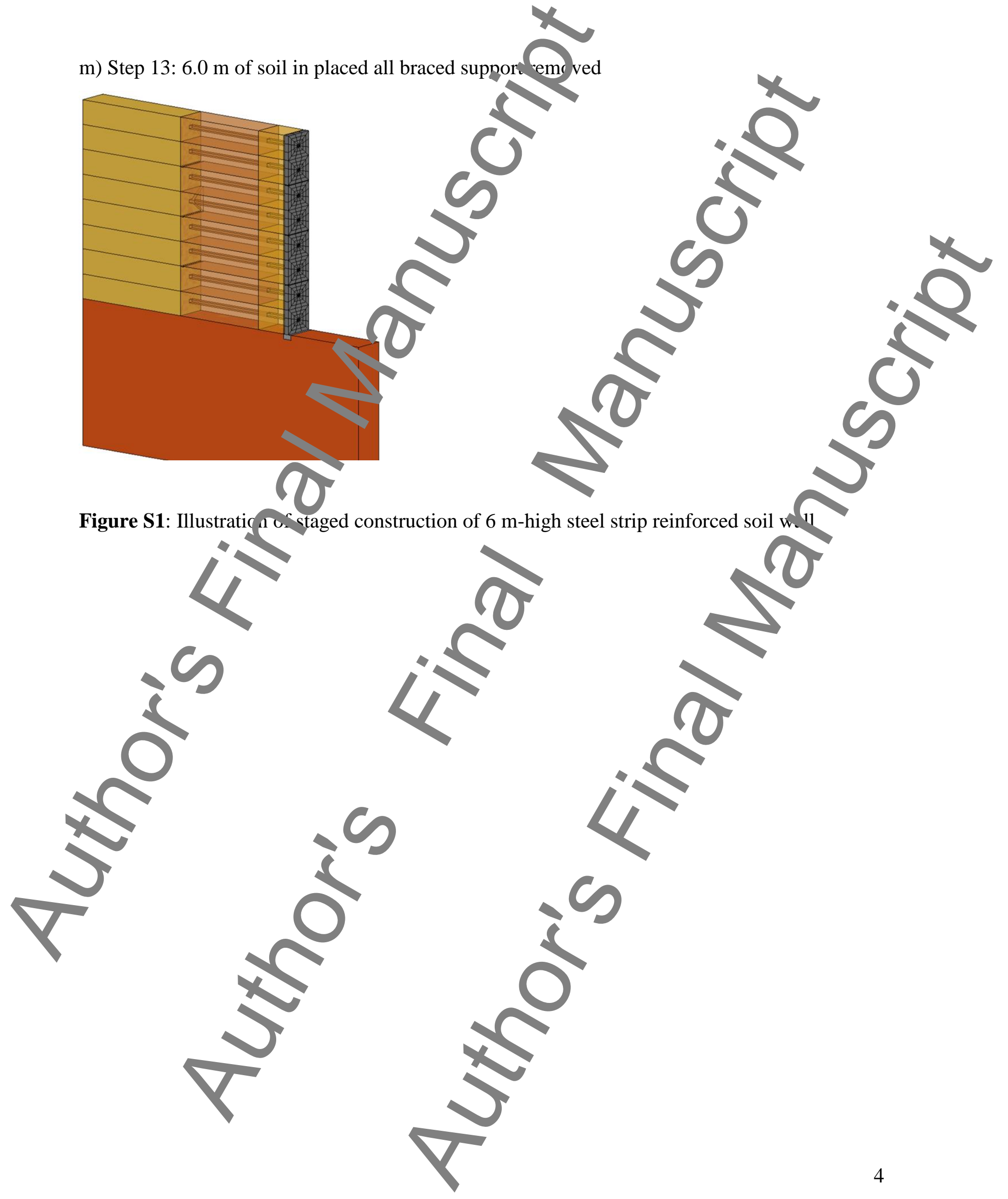




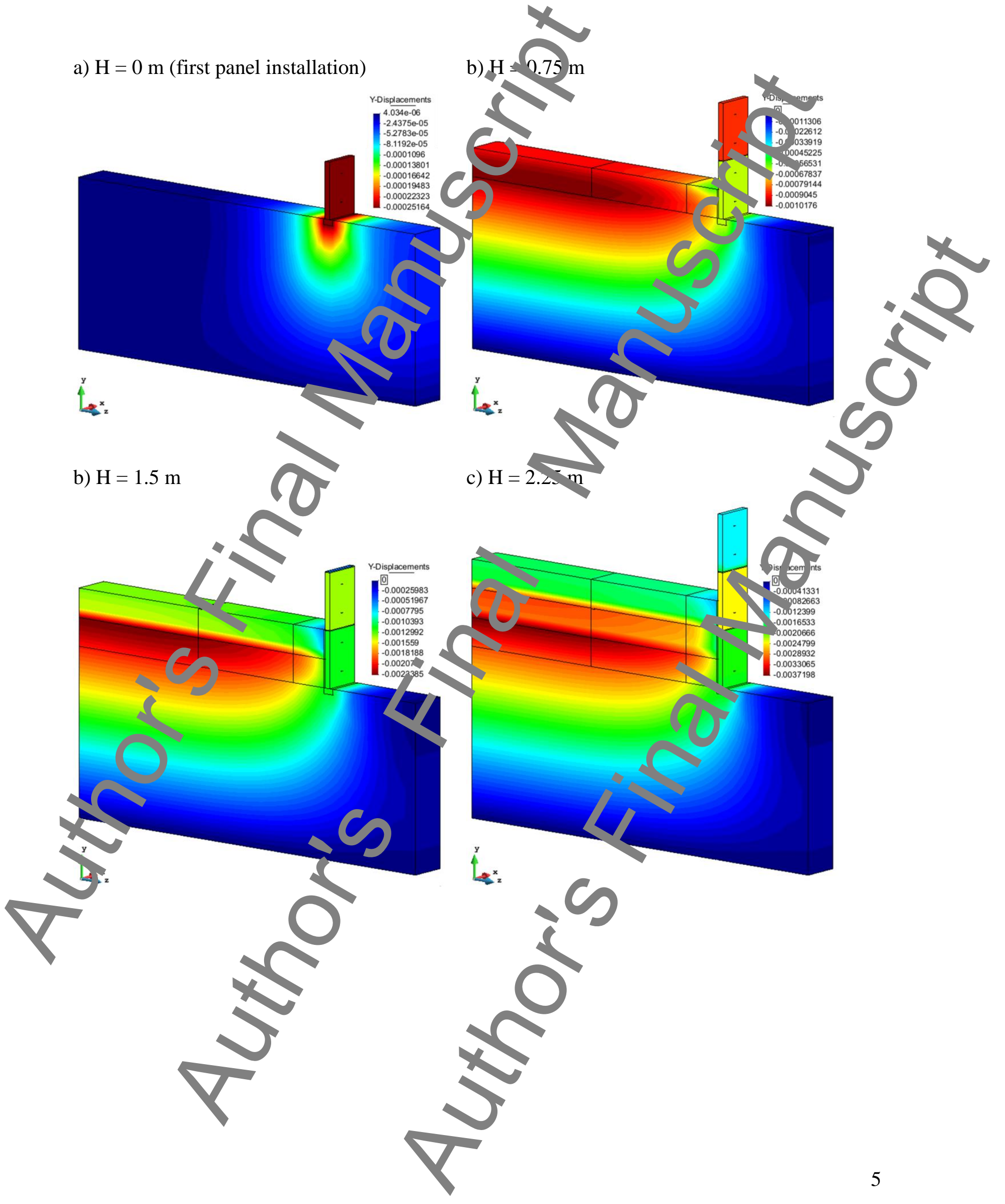




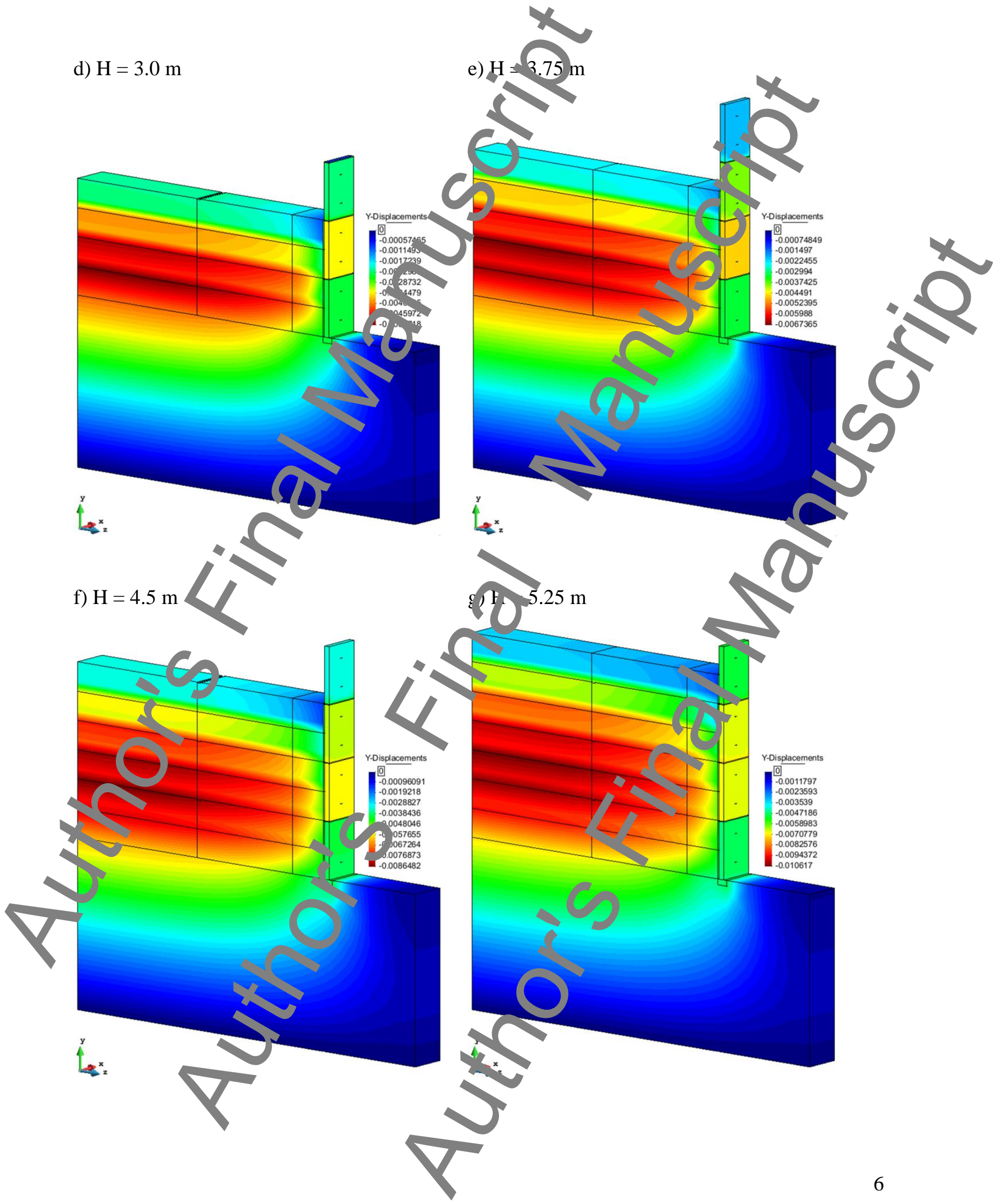




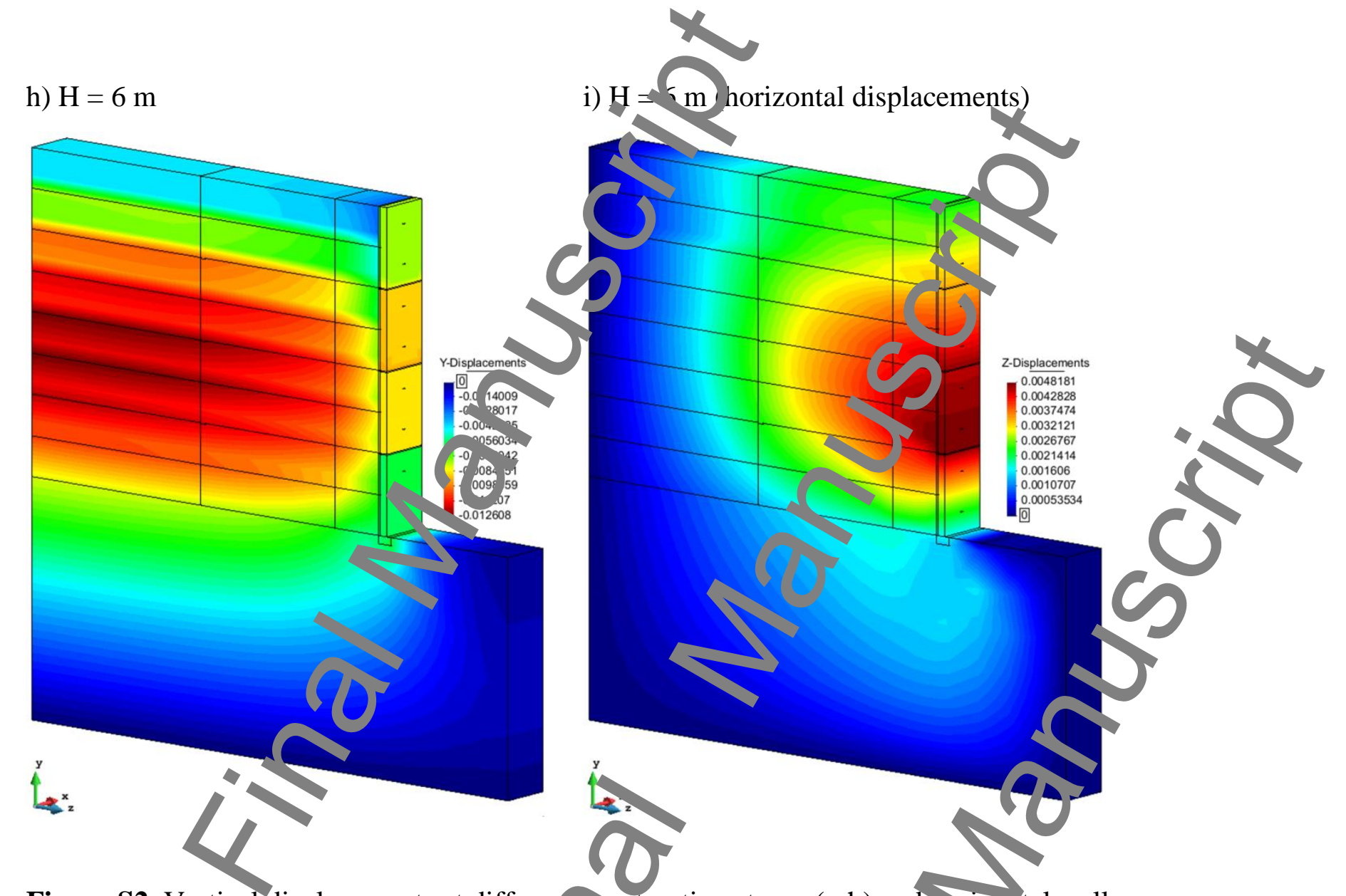

Figure S2. Vertical displacements at differer construction stages (a-h) and hrizontal wall displaceme at end of construction $\mathrm{H}=6 \mathrm{~m}$ (1, (units: $\mathrm{m}$ ) (Case 0 - sted strip wall)

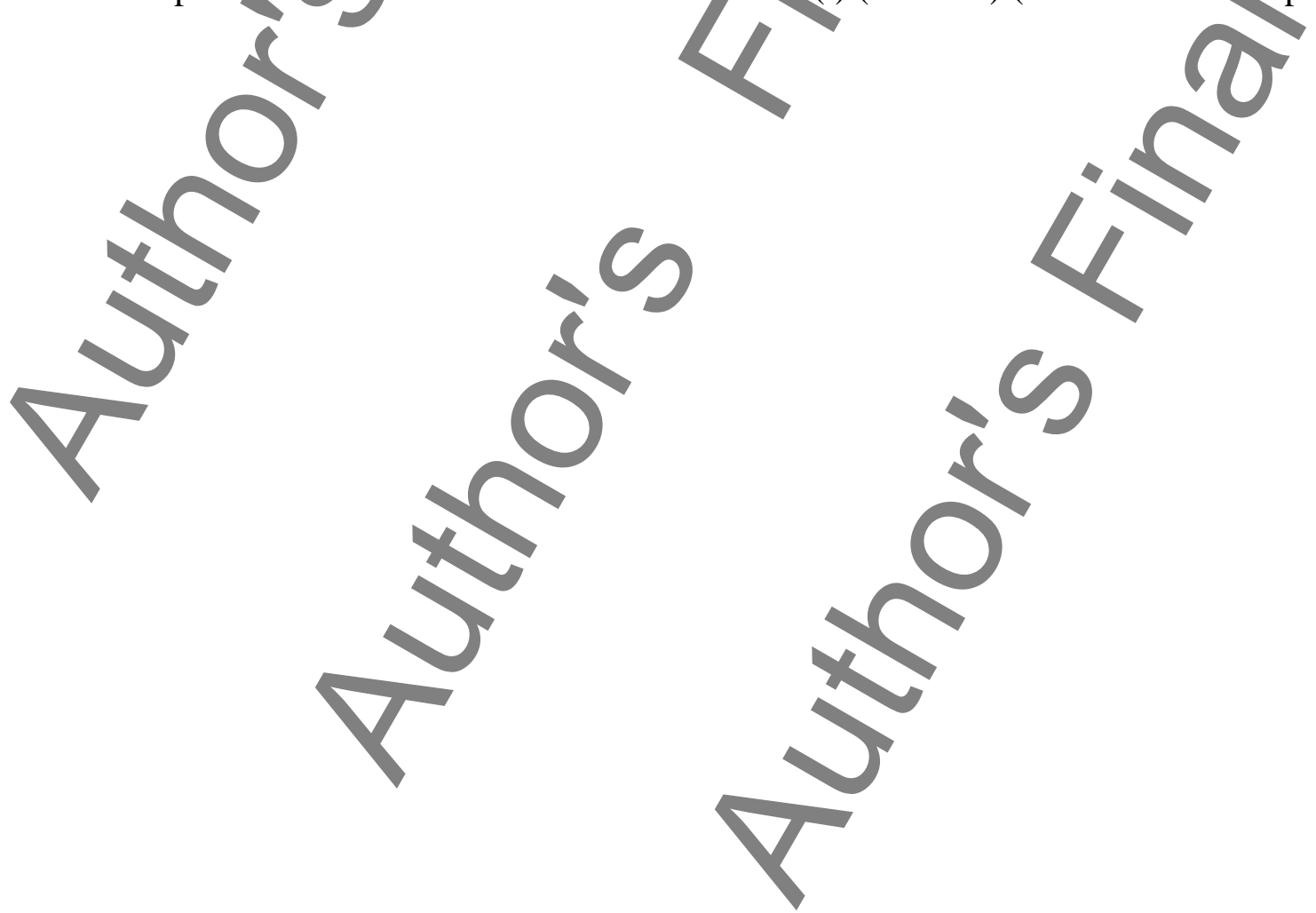




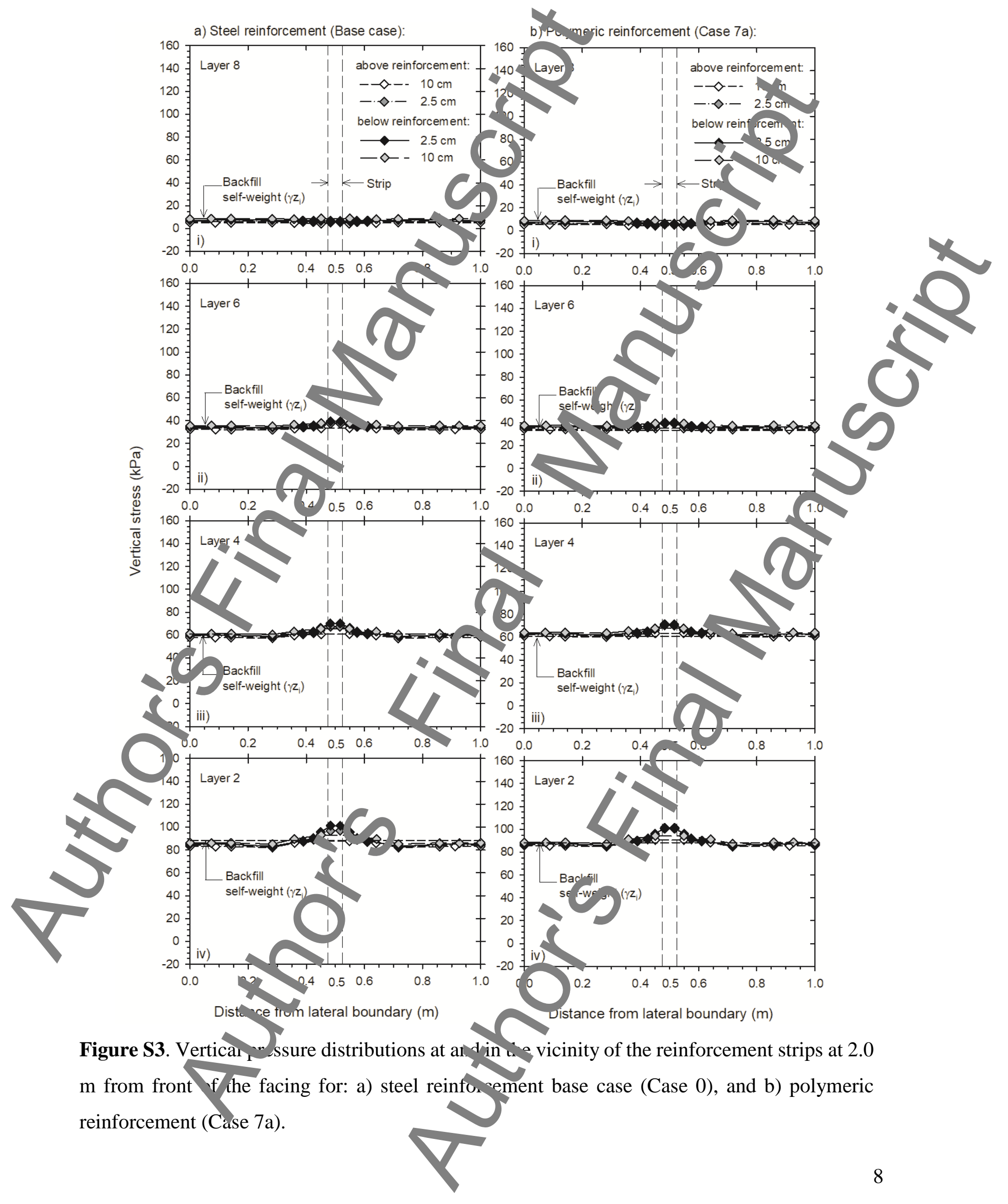


a) vertical stresses $(\mathrm{MPa})$

b) horizonaly stresses $(\mathrm{MPa})$ in reinforcement

direc ion
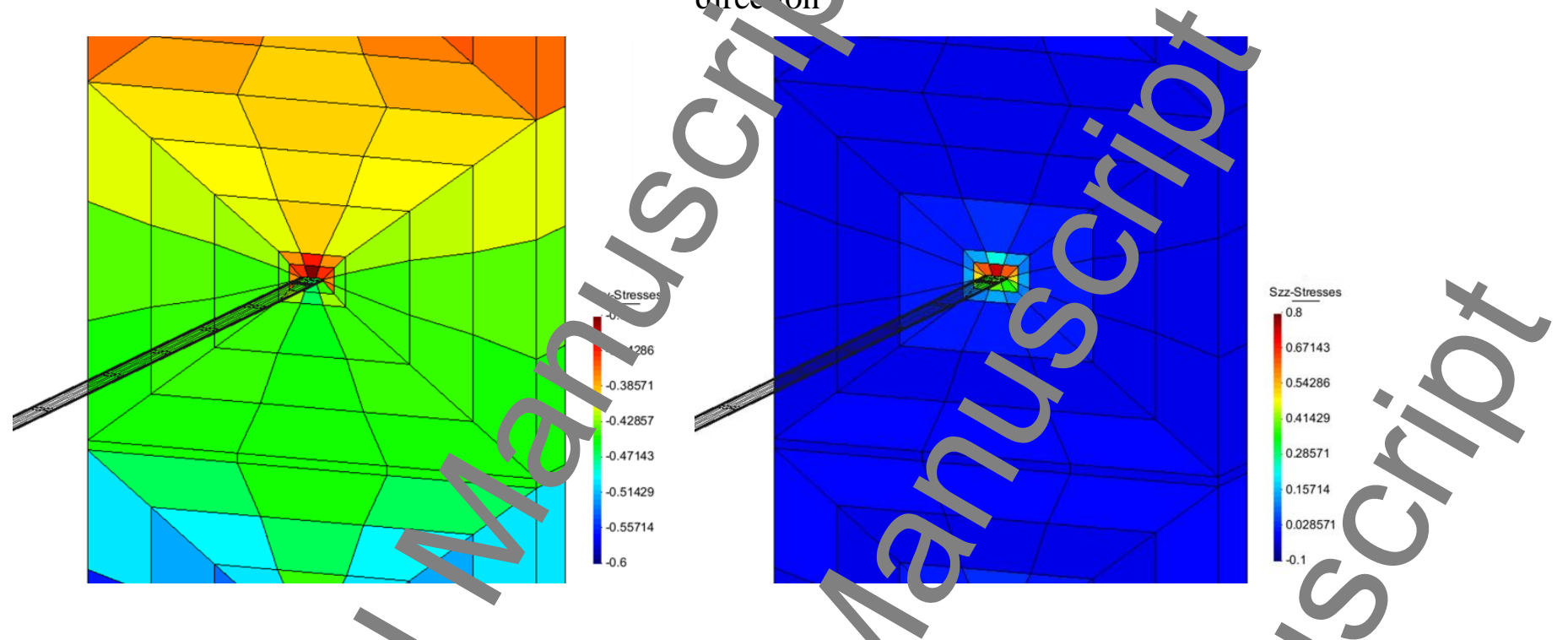

c) horizontal stresses (NPá in wall face direction
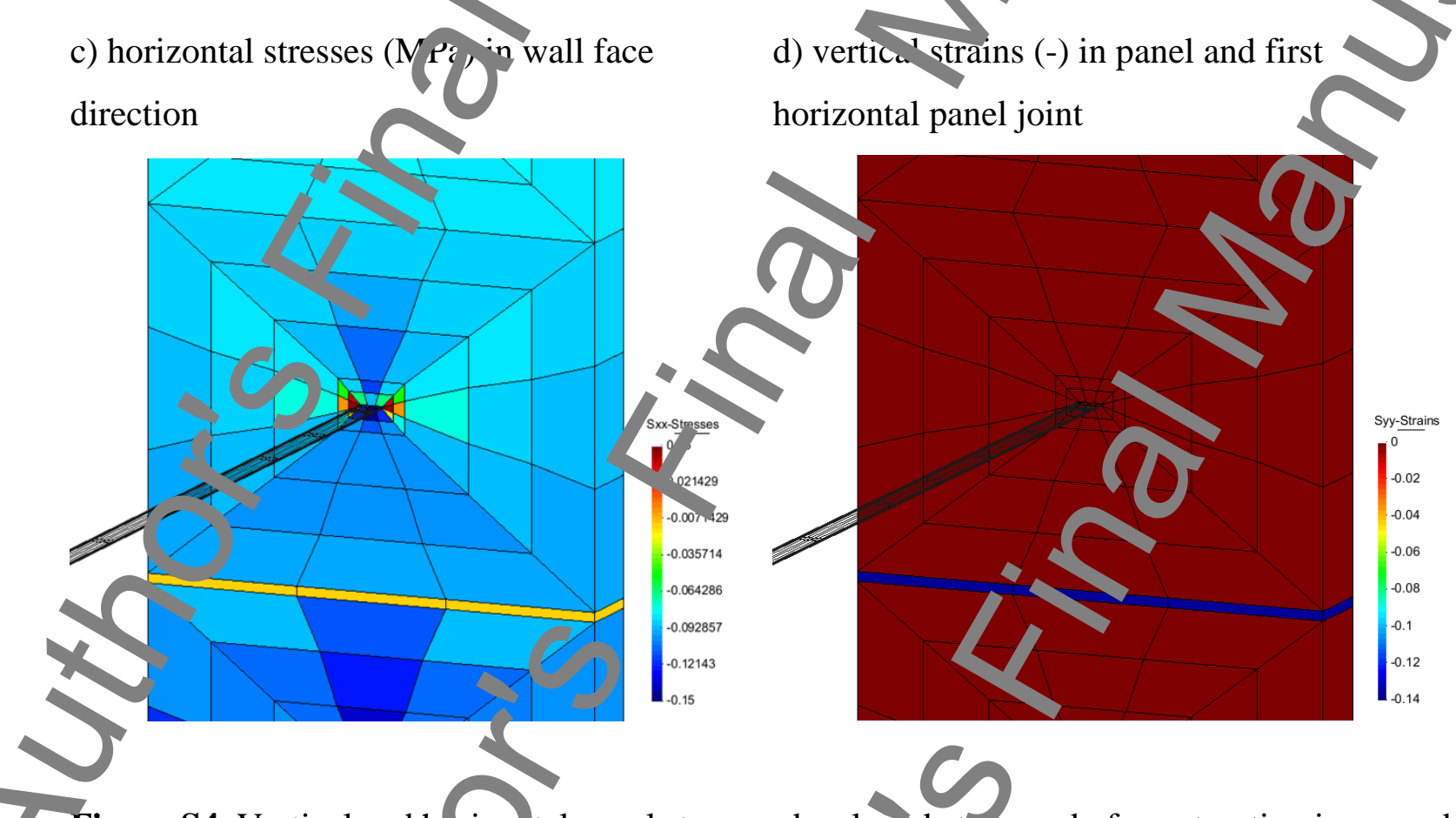

Figure S4. Vertical and h rizo tal panel stresses developed at the end of construction in second panel from bottom or te wall and vertical strains (steel surin wall - Case 0).
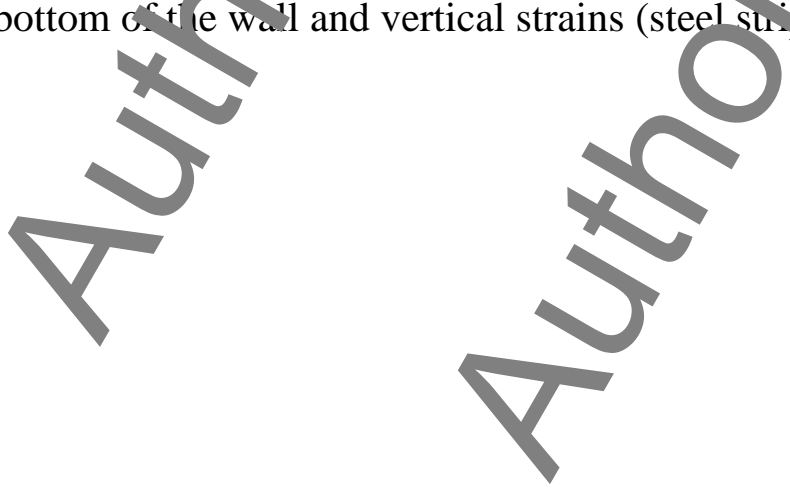
Table S1. Parameters used to simulate PWRI wall (from net al. 2015a)

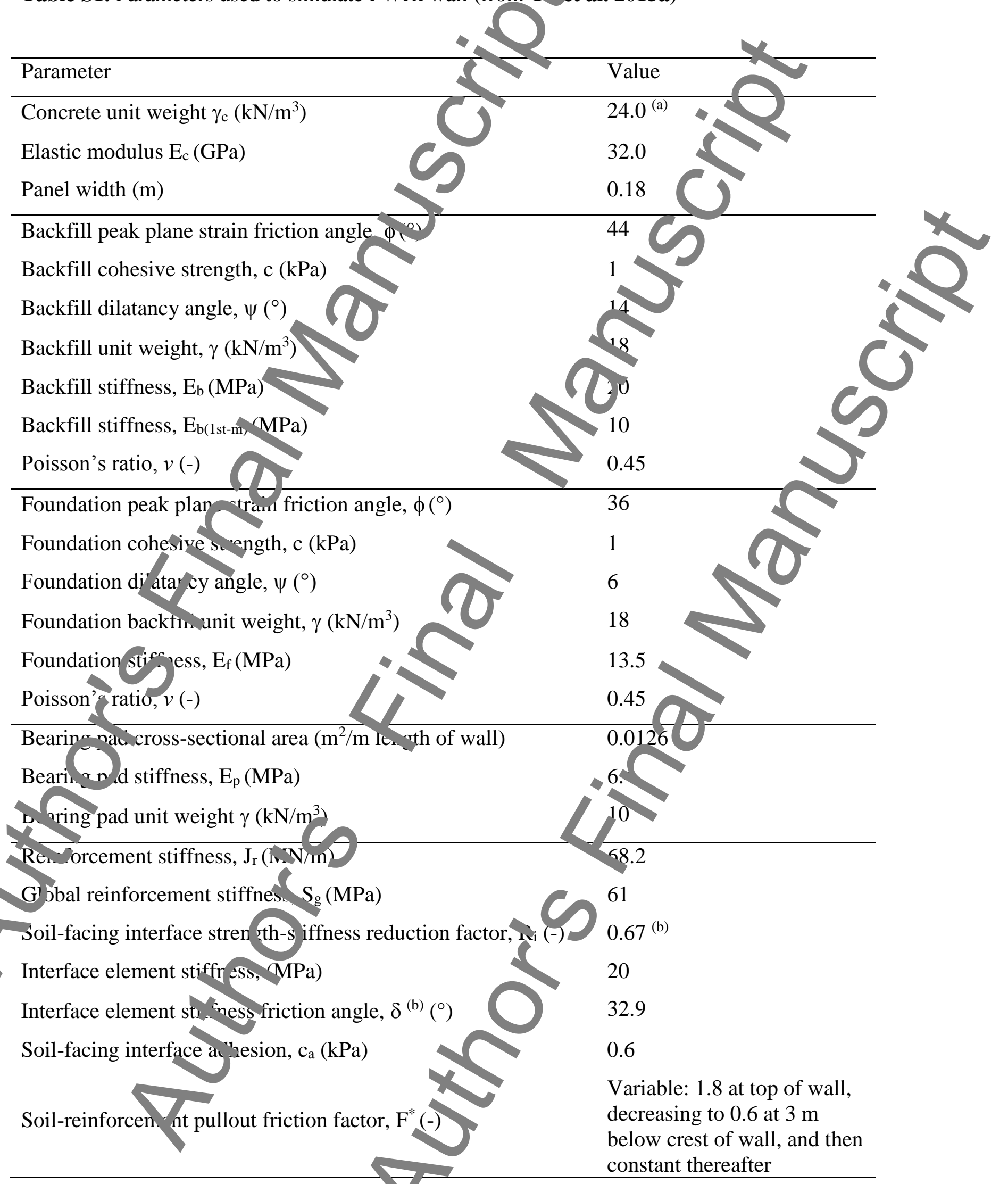




\section{Notes:}

(a) Unit weight of concrete in numerical model wa inc eased by a factor of $0.180 / 0.150$ to account for the wider panel width $(180 \mathrm{~mm})$ in $\mathrm{mh}$. ical wall and the Yu et $\mathrm{m}$ model, and the narrower panel width $(150 \mathrm{~mm})$ used for th numerical PWRI wall in the curent study.

(b) Applied to backfill soil only to calculate modurus of soil-facing stiffnes ad iesion and interface soil friction angle.

(c) The equivalent steel modulus for the ste 1 s in the PWRI wall using is same width and thickness of the steel strips in Figure $2 \mathrm{~h}$ is $\mathrm{C}=272.6 \mathrm{GPa}$.

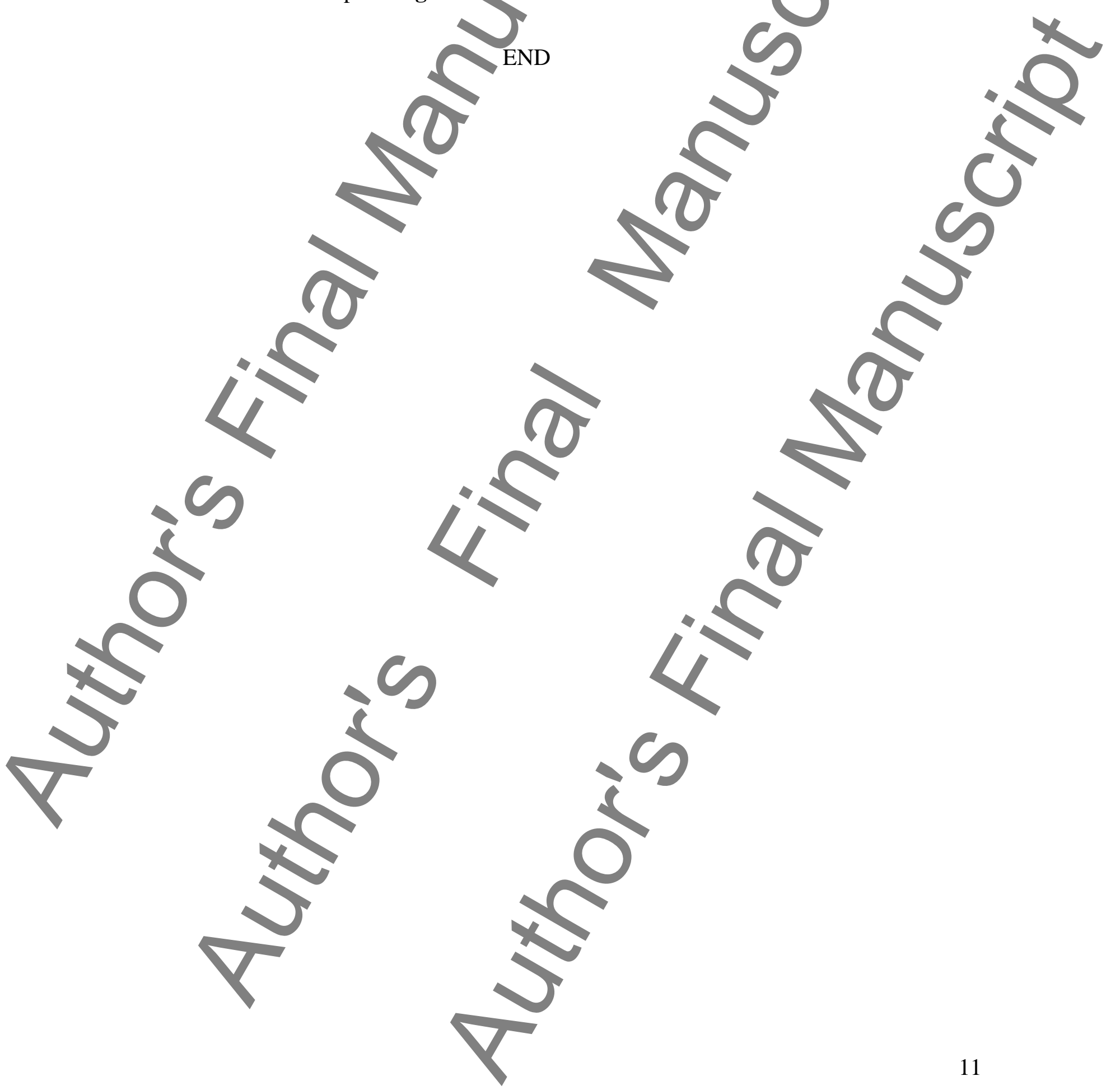

